University of Nebraska - Lincoln

DigitalCommons@University of Nebraska - Lincoln

$5-12-2004$

\title{
Tyrosine B10 Inhibits Stabilization of Bound Carbon Monoxide and Oxygen in Soybean Leghemoglobin
}

\author{
Suman Kundu \\ lowa State UniVersity, Ames, lowa \\ George C. Blouin \\ Rice UniVersity, Houston, Texas \\ Scott A. Premer \\ Gautam Sarath \\ University of Nebraska-Lincoln, Gautam.sarath@ars.usda.gov \\ John S. Olson \\ Rice University, olson@rice.edu \\ See next page for additional authors
}

Follow this and additional works at: https://digitalcommons.unl.edu/usdaarsfacpub

Part of the Agricultural Science Commons

Kundu, Suman; Blouin, George C.; Premer, Scott A.; Sarath, Gautam; Olson, John S.; and Hargrove, Mark S., "Tyrosine B10 Inhibits Stabilization of Bound Carbon Monoxide and Oxygen in Soybean Leghemoglobin" (2004). Publications from USDA-ARS / UNL Faculty. 30.

https://digitalcommons.unl.edu/usdaarsfacpub/30

This Article is brought to you for free and open access by the U.S. Department of Agriculture: Agricultural Research Service, Lincoln, Nebraska at DigitalCommons@University of Nebraska - Lincoln. It has been accepted for inclusion in Publications from USDA-ARS / UNL Faculty by an authorized administrator of DigitalCommons@University of Nebraska - Lincoln. 


\section{Authors}

Suman Kundu, George C. Blouin, Scott A. Premer, Gautam Sarath, John S. Olson, and Mark S. Hargrove 


\title{
Tyrosine B10 Inhibits Stabilization of Bound Carbon Monoxide and Oxygen in Soybean Leghemoglobin ${ }^{\dagger}$
}

\author{
Suman Kundu, ${ }^{\ddagger}$ George C. Blouin,${ }^{\S}$ Scott A. Premer,${ }^{\ddagger}$ Gautam Sarath,${ }^{\perp}$ John S. Olson,${ }^{\S}$ and Mark S. Hargrove ${ }^{*, \sharp}$ \\ Department of Biochemistry, Biophysics and Molecular Biology, Iowa State University, Ames, Iowa 50011, \\ Department of Biochemistry and Cell Biology and the W. M. Keck Center for Computational Biology, Rice University, \\ Houston, Texas 77005, and U.S. Department of Agriculture and University of Nebraska, Lincoln, Nebraska 68502
}

Received January 20, 2004; Revised Manuscript Received March 15, 2004

\begin{abstract}
Detailed comparisons of the carbon monoxide FTIR spectra and ligand-binding properties of a library of E7, E11, and B10 mutants indicate significant differences in the role of electrostatic interactions in the distal pockets of wild-type sperm whale myoglobin and soybean leghemoglobin. In myoglobin, strong hydrogen bonds from several closely related conformations of the distal histidine $\left(\mathrm{His}^{\mathrm{E} 7}\right)$ side chain preferentially stabilize bound oxygen. In leghemoglobin, the imidazole side chain of $\mathrm{His}^{\mathrm{E} 7}$ is confined to a single conformation, which only weakly hydrogen bonds to bound ligands. The phenol side chain of $\mathrm{Tyr}^{\mathrm{B} 10}$ appears to "fix" the position of His ${ }^{\mathrm{E} 7}$, probably by donating a hydrogen bond to the $\mathrm{N} \delta$ atom of the imidazole side chain. The proximal pocket of leghemoglobin is designed to favor strong coordination bonds between the heme iron and axial ligands. Thus, high oxygen affinity in leghemoglobin is established by a favorable staggered geometry of the proximal histidine. The interaction between $\mathrm{His}^{\mathrm{E} 7}$ and $\mathrm{Tyr}^{\mathrm{B} 10}$ prevents overstabilization of bound oxygen. If hydrogen bonding from $\mathrm{His}^{\mathrm{E}}{ }^{7}$ were as strong as it is in mammalian myoglobin, the resultant ultrahigh affinity of leghemoglobin would prevent oxygen transport in root nodules.
\end{abstract}

Myoglobin $\left(\mathrm{Mb}^{1}\right)$ and leghemoglobin ( $\mathrm{Lb}$ ) perform similar physiological roles in their respective environments. Both facilitate the diffusion of oxygen by increasing its effective concentration in either muscle $(\mathrm{Mb})$ or root nodule $(\mathrm{Lb})$ tissue. Each protein exhibits the requisite rate constants for transport, but Lb has a 20-fold higher affinity for oxygen because it must maintain lower free oxygen concentrations to prevent inhibition of the nitrogenase complex in the root nodule $(1,2)$. The two proteins share a globin fold that originally led to the assumption that they function similarly at the molecular level (3). However, recent detailed studies of soybean leghemoglobin (Lba) indicate that it uses a mechanism to regulate ligand binding distinct from that of $\mathrm{Mb}$ (4-9).

Mutagenesis studies have shown that proximal contributions to $\mathrm{O}_{2}$ affinity are quite different in Lba compared to those in sperm whale $\mathrm{Mb}(6)$. In Lba, the plane of the His ${ }^{\mathrm{F} 8}$

\footnotetext{
Supported by NSF Grant MCB-0077890 (M.S.H.), USDA Grant 99-35306-7833 (M.S.H.), the Iowa State University Plant Sciences Institute (M.S.H.), U.S. Public Health Service Grants GM 35649 (J.S.O.) and HL 47020 (J.S.O.), and Grant C-612 (J.S.O.) from the Robert A. Welch Foundation. G.C.B. is the recipient of a traineeship from Training Grant GM08280.

* Author to whom correspondence should be addressed [telephone (515) 294-2616; fax (515) 294-0453; e-mail msh@iastate.edu].

Iowa State University.

$\S$ Rice University.

${ }^{\perp}$ U.S. Department of Agriculture and University of Nebraska.

${ }^{1}$ Abbreviations: FTIR, Fourier transform infrared resonance; $v_{\mathrm{CO}}$, $\mathrm{C}-\mathrm{O}$ stretching frequency; Lba, soybean leghemoglobin $\mathrm{a} ; \mathrm{Mb}$, myoglobin; rice $\mathrm{nsHb}$, rice nonsymbiotic hemoglobin I; lupin Lb, yellow lupine leghemoglobin I; cowpea Lb, cowpea leghemoglobin II; Hb, hemoglobin; IPTG, isopropyl- $\beta$-D-thiogalactoside; CO, carbon monoxide.
}

imidazole side chain is staggered with respect to the pyrrole nitrogen atoms of the porphyrin ring. This orientation favors in-plane movement of the iron atom and strong axial ligand coordination. In all mammalian $\mathrm{Mbs}$, the $\mathrm{His}^{\mathrm{F} 8}$ side chain is in an eclipsed geometry that inhibits ligand coordination $(10-12)$. These ideas were confirmed directly by swapping the $\mathrm{F}$ helices between Lba and sperm whale $\mathrm{Mb}(6)$. Thus, both stereochemical arguments and direct experimental measurements show that the Lba proximal heme pocket favors high oxygen affinity.

Stabilization of bound ligands by hydrogen bonding in the distal pocket of Lba is weakened to prevent an ultrahigh $\mathrm{O}_{2}$ affinity that would inhibit transport in root nodules. This idea is supported by comparative mutagenesis experiments with recombinant Lbs and Mbs containing altered distal pockets $(4,5,13-15)$. His ${ }^{\mathrm{E} 7}$ in $\mathrm{Mb}$ forms a strong hydrogen bond with bound oxygen, and replacement with non-hydrogenbonding amino acids greatly decreases $\mathrm{O}_{2}$ affinity. In contrast, homologous $\mathrm{His}^{\mathrm{E} 7}$ substitutions in Lba have very little effect on ligand affinity. Comparison of rate constants for ligand binding to wild type and distal pocket mutants of soybean Lba suggests that the unusual combination of $\mathrm{His}^{\mathrm{E} 7}$ and $\mathrm{Tyr}^{\mathrm{B} 10}$ works together to prevent $\mathrm{His}^{\mathrm{E} 7}$ from forming a strong hydrogen bond with bound $\mathrm{O}_{2}$ (5). To test this hypothesis, we have used FTIR spectroscopy to examine electrostatic fields and hydrogen-bonding interactions in the vicinity of bound $\mathrm{CO}$ for a complete set of $\mathrm{Lba}$ and $\mathrm{Mb}$ distal pocket mutants.

The IR spectrum of bound $\mathrm{CO}$ is a sensitive measurement of hydrogen-bonding and electrostatic interactions near the ligand (16-24). In native mammalian $\mathrm{MbCO}$, the $\mathrm{C}-\mathrm{O}$ 


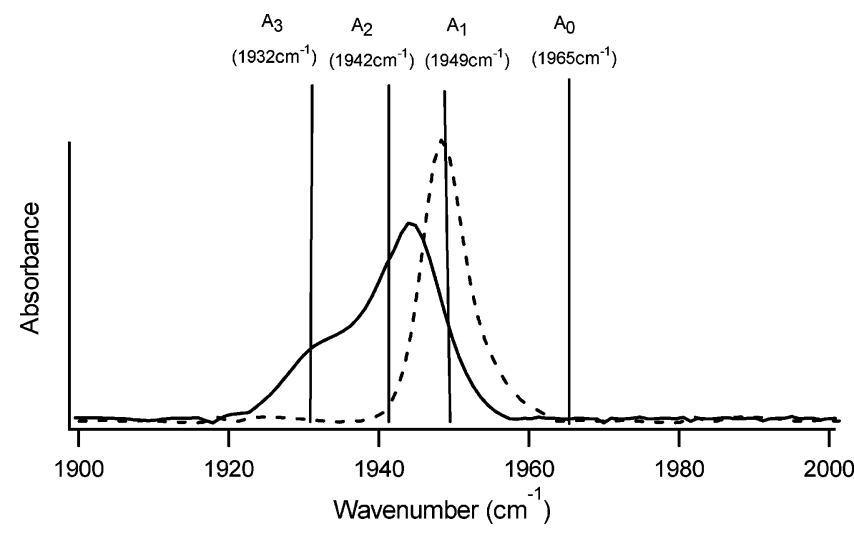

FIGURE 1: Comparison of the IR spectra of wild-type sperm whale $\mathrm{MbCO}$ and soybean LbaCO. The spectrum of MbCO (solid line) contains two major $v_{\mathrm{CO}}$ peaks, one at $1945 \mathrm{~cm}^{-1}$, representing a combination of the $A_{1}$ and $A_{2}$ conformers, and another at 1932 $\mathrm{cm}^{-1}$, representing the $A_{3}$ conformer with a stronger hydrogen bond between $\mathrm{His}^{\mathrm{E} 7}$ and bound $\mathrm{CO}$. LbaCO (broken line) exists as a single conformer with a peak at $1948 \mathrm{~cm}^{-1}$.

stretching frequency $\left(v_{\mathrm{CO}}\right)$ senses the proximity of the distal His and whether the $\mathrm{N} \epsilon-\mathrm{H}$ tautomer is donating a proton to the carbonyl $\mathrm{O}$ atom. The $\mathrm{CO}$ complexes of many $\mathrm{Hbs}$ and Mbs display multiple stretching frequencies between 1900 and $2000 \mathrm{~cm}^{-1}$, with the major $v_{\mathrm{CO}}$ peaks designated $v_{0}, v_{1}$, $v_{2}$, etc., in the descending order of their frequencies (19). The structural origins of these multiple conformational substates have been studied in great detail for sperm whale $\mathrm{MbCO}$. The designations $\mathrm{A}_{0}, \mathrm{~A}_{1-2}, \mathrm{~A}_{3}$ (Figure 1) represent discrete conformations of ground-state native $\mathrm{MbCO}$ with $v_{\text {CO }}$ peaks at 1965,1945 , and $1932 \mathrm{~cm}^{-1}$, respectively, based on low-temperature time-resolved IR experiments by Frauenfelder's group and deconvolution analyses of room temperature IR spectra by Caughey and co-workers $(18,19,23$, 25-28).

$\mathrm{Li}$ and Spiro (29) interpreted the various $v_{\mathrm{CO}}$ bands in terms of different extents of back-bond donation from the iron atom. They suggested that proton donors adjacent to the $\mathrm{O}$ atom of the bound ligand enhance the degree of backbonding, increasing the order of the $\mathrm{Fe}-\mathrm{C}$ bond and decreasing the order of the $\mathrm{C}-\mathrm{O}$ bond due to the formation of $\mathrm{Fe}^{\delta(+)}=\mathrm{C}=\mathrm{O}^{\delta(-)}$ resonance structures. The loss of hydrogen bonding or the presence of a negative electrostatic potential would reverse these effects. Oldfield et al. proposed short-range electric field-induced $v_{\mathrm{CO}}$ frequency shifts due to $180^{\circ}$ ring flips of the tautomers of the distal His and its movement away from the bound ligand at low $\mathrm{pH}(30,31)$. It was assumed that the distal His dominates the interaction with the bound ligand due to its proximity to $\mathrm{CO}$ and that enhancement, weakening, or loss of interaction with this residue accounted for all four conformers of $\mathrm{MbCO}$.

More recently, Phillips, Olson, Franzen, and co-workers considered longer range interactions from internal fields arising from a sum of smaller interactions at a distance, as well as specific short-range hydrogen-bonding interactions with $\mathrm{His}^{\mathrm{E} 7}$ and other adjacent amino acid side chains (19, 32). They concluded that, if the proximal geometry remains invariant, $v_{\mathrm{CO}}$ is a reflection of the electrostatic fields and hydrogen-bonding interactions exerted by amino acid side chains close to bound $\mathrm{CO}$ and by itself does not unambiguously define a conformational substate $(18,19,33)$. A positive potential or strong hydrogen bond donation lowers
$v_{\mathrm{CO}}$, whereas a negative potential or loss of hydrogen bonding increases $v_{\mathrm{CO}}$. Phillips et al. (19) also showed that there is a strong correlation between the average peak value, $\bar{v}_{\mathrm{CO}}$, and the logarithm of the rate constant for $\mathrm{O}_{2}$ dissociation, $k_{\mathrm{O} 2}$, for a series of 20 different Mbs. Thus, in Mb both $\bar{v}_{\mathrm{CO}}$ and $k_{\mathrm{O} 2}$ reflect the strength of hydrogen-bonding interactions between distal pocket amino acids and bound ligands.

In sperm whale $\mathrm{MbCO}$, the principal $\mathrm{CO}$ stretching bands are $v_{0}=1965 \mathrm{~cm}^{-1}, v_{1}=1949 \mathrm{~cm}^{-1}, v_{2}=1942 \mathrm{~cm}^{-1}$, and $v_{3}=1932 \mathrm{~cm}^{-1}$, which have been assigned to the $\mathrm{A}_{0}, \mathrm{~A}_{1}$, $\mathrm{A}_{2}$, and $\mathrm{A}_{3}$ conformational substates of the $\mathrm{His}^{\mathrm{E} 7}$ side chain (Figure 1; 16, 21, 22, 25, 26, 34, 35). At neutral pH, the dominant band is at $1945 \mathrm{~cm}^{-1}$ and represents an average peak position for the $A_{1}$ and $A_{2}$ conformers, often simply called $\mathrm{A}_{1}$. A minor $\mathrm{A}_{3}$ substate is observed at $v_{\mathrm{CO}} \approx 1932$ $\mathrm{cm}^{-1}$ (18). At low $\mathrm{pH}$, the distal His swings out into the solvent, creating an apolar active site with $v_{\mathrm{CO}}=\sim 1960$ $\mathrm{cm}^{-1}$. This $\mathrm{Mb}$ conformer is designated the $\mathrm{A}_{0}$ substate.

In contrast, Lba shows a narrow $\mathrm{CO}$ stretching frequency band at $1948 \mathrm{~cm}^{-1}$, indicating a single well-defined conformation at neutral $\mathrm{pH}$ (Figure 1) (36). This result suggests that the distal His in $\mathrm{LbaCO}$ is more restricted under physiological conditions than in sperm whale $\mathrm{Mb}$, which exhibits significant conformational heterogeneity. In a series of high-resolution NMR studies, Mabbutt et al. $(37,38)$ observed that the imidazole ring of $\mathrm{His}^{\mathrm{E} 7}$ in $\mathrm{LbaCO}$ appears to be "flipped" with respect to the orientation in sperm whale $\mathrm{MbCO}$ by a $180^{\circ}$ rotation about the $\mathrm{C} \beta-\mathrm{C} \gamma$ bond. As a result, $\mathrm{N} \delta$ points upward, away from the heme plane and toward the protein interior, but $\mathrm{N} \epsilon$ is still close to the bound ligand. The $\mathrm{N} \epsilon-\mathrm{H}$ tautomer of $\mathrm{His}^{\mathrm{E} 7}$ must still be dominant because the $v_{\mathrm{CO}}$ peak of $\mathrm{LbaCO}\left(1948 \mathrm{~cm}^{-1}\right)$ is similar in position to $\bar{v}_{\mathrm{CO}}$ for $\mathrm{MbCO}\left(1941 \mathrm{~cm}^{-1}\right)$, even though the 7 $\mathrm{cm}^{-1}$ shift to higher frequency does indicate a weaker hydrogen-bonding interaction in the plant protein.

Regulation of the position of $\mathrm{His}^{\mathrm{E} 7}$ and its hydrogenbonding potential has been suggested as a possible mechanism for attenuating ligand affinity in Lba (5). As described above, FTIR spectroscopy is an ideal tool for assessing the effects of distal pocket mutations on the electrostatic and/or hydrogen-bonding environment of bound $\mathrm{CO}$ and for testing structural mechanisms for regulation of ligand binding. In the present study, $\mathrm{CO}$ stretching frequencies for a comprehensive set of distal pocket mutants of Lba have been measured. The results have been compared to IR spectra of equivalent mutants of sperm whale $\mathrm{Mb}$. In both proteins, $\mathrm{Tyr}^{\mathrm{B} 10}$ appears to inhibit hydrogen-bonding interactions between $\mathrm{His}^{\mathrm{E} 7}$ and bound $\mathrm{CO}$ and $\mathrm{O}_{2}(5,13)$. The new IR and previous $\mathrm{O}_{2}$ binding and NMR results suggest that there is a direct interaction between the $\mathrm{His}^{\mathrm{E} 7}$ and $\mathrm{Tyr}^{\mathrm{B} 10}$ side chains in Lba that weakens stabilization of bound ligands.

\section{MATERIALS AND METHODS}

Preparation, Expression, and Purification of Proteins. Site-directed mutant cDNAs were constructed, and recombinant Mbs and Lbs were expressed and purified as described previously $(4-6,18)$. Mutations were introduced at the key helix positions E7, E11, and B10 (Figure 2). Yellow lupine leghemoglobin I (lupin Lb) cDNA in pET 3a was provided by Dr. Pawel M. Strozycki, Institute of Bioorganic Chemistry, Polish Academy of Sciences, Poland. The lupin Lb 


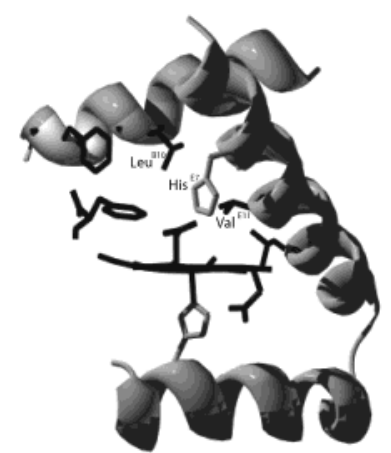

(A) sperm whale $\mathrm{Mb}$

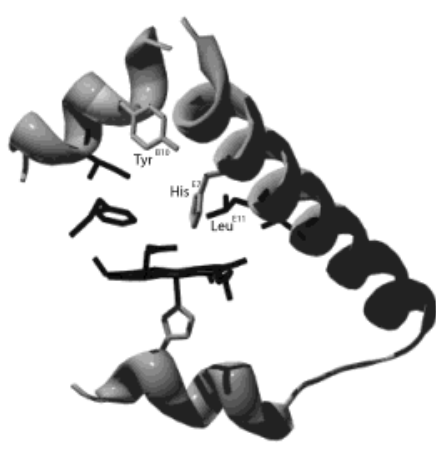

(B) soybean Lba

FIGURE 2: Amino acid side chains in the heme pockets of (A) sperm whale $\mathrm{Mb}$ and $(\mathrm{B})$ soybean Lba. The polar side chains are in gray and the apolar ones in black. The key amino acids (B10, E7, and E11) are labeled. His ${ }^{\mathrm{E} 7}$, the seventh residue on the E helix and 64th residue on the polypeptide chain, is the only polar side chain in $\mathrm{Mb}$ close enough to directly interact with the bound ligand. In Lba, however, both $\mathrm{His}^{\mathrm{E} 7}$ (61st residue) and $\mathrm{Tyr}^{\mathrm{B} 10}$ (30th residue) are polar, but only $\mathrm{His}^{\mathrm{E} 7}$ is close enough to the iron to interact directly with diatomic ligands. The $\mathrm{Mb}$ and Lba structures were taken from Quillin et al. (47) [Protein Data Bank (PDB) 2MBW] and Hargrove et al. (4) (PDB 1BIN), respectively.

cDNA was subcloned into Novagen expression vector $\mathrm{pET}$ 29a between $N d e I$ and $E c o$ RI restriction sites and expressed in Escherichia coli BL21( $\lambda$ DE3)-CodonPlus-RP cells (Stratagene) grown in $2 \times \mathrm{YT}$ medium at $37{ }^{\circ} \mathrm{C}$. The medium in shake flasks was supplemented with $50 \mu \mathrm{g} / \mathrm{mL}$ kanamycin and $25 \mu \mathrm{g} / \mathrm{mL}$ chloramphenicol. Approximately $6.5 \mathrm{~h}$ after inoculation, expression was induced with $0.5 \mathrm{mM}$ IPTG. After induction, the growth was continued for a further 15 $\mathrm{h}$, resulting in red cell pellet. The lupin LbI protein was purified in the same way as soybean Lba (6). Cowpea leghemoglobin II (cowpea Lb) was purified according to methods described previously (39). All samples were oxidized and stored in the ferric form.

FTIR Spectroscopy and Kinetic Measurements. Samples of CO-bound and deoxygenated Lba and $\mathrm{Mb}$ were prepared in stoppered Eppendorf tubes equilibrated with 1 atm of either $\mathrm{CO}$ or $\mathrm{N}_{2}$. Approximately $20 \mu \mathrm{L}$ of $2-3 \mathrm{mM}$ protein was aliquoted into this tube with a syringe. The Eppendorf tube was then re-equilibrated with either pure $\mathrm{CO}$ or $\mathrm{N}_{2}$ gas. One microliter of a $200 \mathrm{mM}$ dithionite solution in $100 \mathrm{mM}$ phosphate buffer, $\mathrm{pH}$ 7.0, was added to the tube to reduce any oxidized iron and to remove molecular oxygen. The tube was vortexed and then spun in a microcentrifuge to remove any precipitate. An airtight syringe, equilibrated with nitrogen gas, was then used to draw $\mathrm{LbaCO}$ or deoxyLba from the tube. The protein sample was rapidly added to $\mathrm{CaF}_{2} \mathrm{BioCell}$ IR cuvette $(5 \mathrm{~mm}$ thickness $\times 50 \mathrm{~mm}$ diameter, separated by a $40 \mu \mathrm{m}$ spacer; BioTools, Inc.) to obtain a uniform, bubble-free film. Then the windows of the cuvette were quickly sealed. The cuvette was placed in the sample chamber of a Nicolet Nexus 470 FTIR spectrometer (Nicolet Instrument Corp., Middleton, WI), which was purged with nitrogen gas $1 \mathrm{~h}$ prior to and then during data collection. Spectra were recorded from 1800 to $2100 \mathrm{~cm}^{-1}$ at $1 \mathrm{~cm}^{-1}$ resolution. Up to 128 interferograms were averaged for both the $\mathrm{HbCO}$ and deoxyHb control samples. The final $\mathrm{FeCO}$ FTIR spectra were corrected for buffer and protein background by computing LbaCO minus deoxyLba difference spectra.

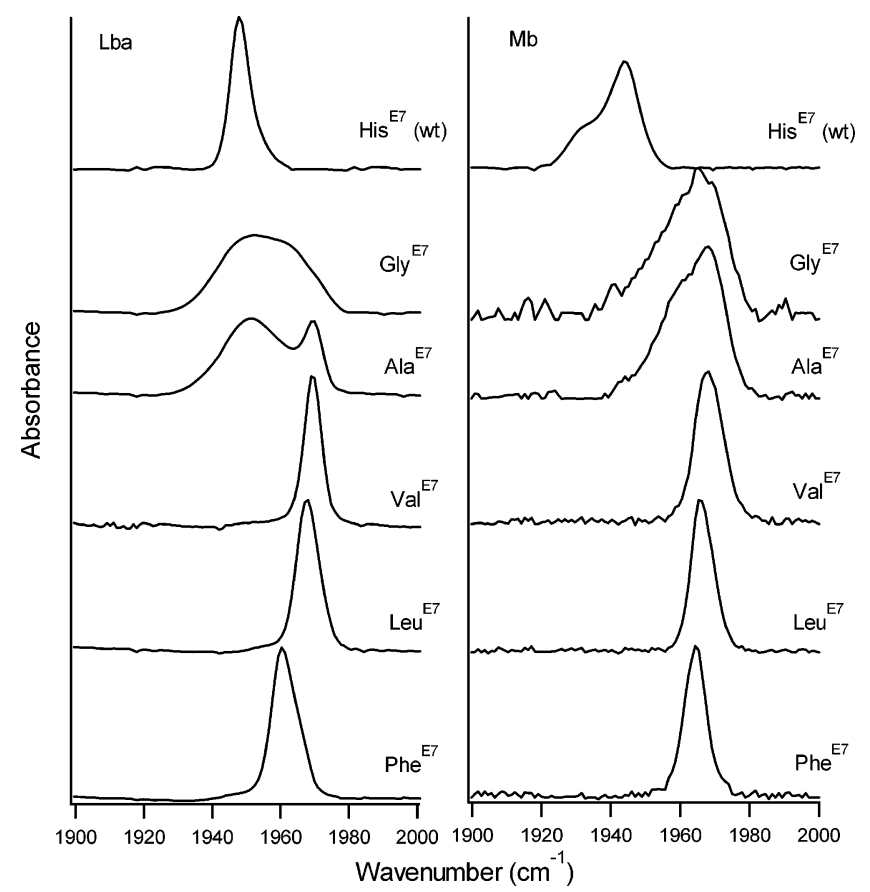

FIGURE 3: IR spectra of $\mathrm{LbaCO}$ and $\mathrm{MbCO}$ mutants with apolar substitutions at position E7. The mutants are designated by a threeletter abbreviation for the substituted amino acid with a superscript denoting the position on the E helix. All of the spectra for the E7 Mb mutants are shifted to higher frequencies due to the loss of hydrogen-bonding interactions with $\mathrm{His}^{\mathrm{E} 7}$. The E7 Lba mutants show similar shifts to higher stretching frequencies. However, the Lba mutants with smaller amino acids at E7 show retention and broadening of the peak at $\sim 1950 \mathrm{~cm}^{-1}$, presumably due to interactions with water molecules entering the "empty" distal pocket. The spectra for the $\mathrm{MbCO}$ mutants were taken from Li et al. (18).

Most of the rate constants for $\mathrm{CO}$ and $\mathrm{O}_{2}$ binding were measured previously (see references in Tables 1-3). The parameters for any new mutants were determined as described in Kundu et al. (5) and Rohlfs et al. (40).

Computations and Molecular Modeling. $\mathrm{Tyr}^{\mathrm{B} 10}$ and $\mathrm{His}^{\mathrm{E} 7}$ rotomers in the Lba-acetate structure (PDB 1BIN) were suitably oriented in the program $\mathrm{O}(41)$ to incorporate the imidazole conformation proposed by Mabbutt et al. $(37,38)$ and to model possible interactions between $\mathrm{Tyr}^{\mathrm{B} 10}$ and $\mathrm{His}^{\mathrm{E}}{ }^{\mathrm{7}}$. NMR chemical shifts for the protons in $\mathrm{Tyr}^{\mathrm{B} 10}$ and $\mathrm{His}^{\mathrm{E} 7}$ side chains were predicted for the proposed model structures using the program SHIFTS (42).

\section{RESULTS}

$H_{i s}{ }^{E 7}$ Hydrogen Bonds to Bound CO Less Strongly in Lba than in $M b$. CO bound to heme within a nonpolar distal pocket typically yields a single IR peak near $1965 \mathrm{~cm}^{-1}$ and is shifted to an average value of $1941 \mathrm{~cm}^{-1}$ in wild-type Mb (Figure 3; Table 1) (18). This blue shift is due to the positive electrostatic field created at the ligand by a hydrogen bond donated from the distal His $(18-20)$. The absorption at $1948 \mathrm{~cm}^{-1}$ by wild-type $\mathrm{LbaCO}$ also implies a hydrogen bond to the bound ligand, although a weaker one compared to $\mathrm{Mb}$. In $\mathrm{Lba}, \mathrm{His}^{\mathrm{E} 7}$ and $\mathrm{Tyr}^{\mathrm{B} 10}$ could potentially serve as proton donors (Figure 2).

The $\mathrm{Phe}^{\mathrm{E} 7}, \mathrm{Leu}^{\mathrm{E} 7}$, and $\mathrm{Val}^{\mathrm{E} 7}$ mutants of Lba show single bands at 1960, 1968, and $1969 \mathrm{~cm}^{-1}$, respectively, indicating the loss of a hydrogen bond from the distal His (Figure 3; 


\begin{tabular}{|c|c|c|c|c|c|c|c|c|c|}
\hline protein & $\begin{array}{l}v_{0}^{b}(\%) \\
\left(\mathrm{cm}^{-1}\right)\end{array}$ & $\begin{array}{l}v_{1,2}(\%) \\
\left(\mathrm{cm}^{-1}\right)\end{array}$ & $\begin{array}{l}v_{3}(\%) \\
\left(\mathrm{cm}^{-1}\right)\end{array}$ & $\begin{array}{c}v_{\mathrm{CO}}^{c} \\
\left(\mathrm{~cm}^{-1}\right)\end{array}$ & protein & $\begin{array}{l}\nu_{0}(\%) \\
\left(\mathrm{cm}^{-1}\right)\end{array}$ & $\begin{array}{l}v_{1,2}(\%) \\
\left(\mathrm{cm}^{-1}\right)\end{array}$ & $\begin{array}{l}v_{3}(\%) \\
\left(\mathrm{cm}^{-1}\right)\end{array}$ & $\begin{array}{c}v_{\mathrm{CO}} \\
\left(\mathrm{cm}^{-1}\right)\end{array}$ \\
\hline wild-type $\mathrm{Lba}^{d}$ & & $1948(100)$ & & 1948 & wild-type $\mathrm{Mb}$ & & $1945^{e}(70)$ & $1932^{e}(30)$ & $1941^{e}$ \\
\hline \multicolumn{5}{|c|}{ His61 (E7) mutants } & \multicolumn{5}{|c|}{ His64 (E7) mutants } \\
\hline $\mathrm{Gly}^{\mathrm{E} 7}$ & $1961(48)$ & $1952(52)$ & & 1956 & Gly ${ }^{\mathrm{E} 7}$ & $1965(100)$ & & & 1965 \\
\hline $\mathrm{Ala}^{\mathrm{E7}}$ & 1969 (49) & $1951(51)$ & & 1959 & $\mathrm{Ala}^{\mathrm{E} 7}$ & $1966(100)$ & & & 1966 \\
\hline $\mathrm{Val}^{\mathrm{E} 7}$ & $1969(100)$ & & & 1969 & $\mathrm{Val}^{\mathrm{E} 7}$ & $1967(100)$ & & & 1967 \\
\hline $\mathrm{Leu}^{\mathrm{E} 7}$ & $1968(100)$ & & & 1968 & $\mathrm{Leu}^{\mathrm{E} 7}$ & $1965(100)$ & & & 1965 \\
\hline $\mathrm{Phe}^{\mathrm{E} 7}$ & $1960(100)$ & & & 1960 & $\mathrm{Phe}^{\mathrm{E} 7}$ & $1964(100)$ & & & 1964 \\
\hline $\operatorname{Trp}^{\mathrm{E} 7}$ & $1959(38)$ & $1940(62)$ & & 1947 & $\operatorname{Trp}^{\mathrm{E7}}$ & $1969(60)$ & $1942(40)$ & & 1958 \\
\hline $\mathrm{Tyr}^{\mathrm{E7}}$ & $1968(55)$ & $1953(45)$ & & 1961 & $\mathrm{Tyr}^{\mathrm{E7}}$ & 1966 (100) & & & 1966 \\
\hline $\mathrm{Gln}{ }^{\mathrm{E} 7}$ & $1957(63)$ & $1943(37)$ & & 1952 & $\mathrm{Gln}{ }^{\mathrm{E} 7}$ & & $1945(100)$ & & 1945 \\
\hline $\mathrm{Lys}^{\mathrm{E} 7}$ & $1968(42)$ & $1959(58)$ & & 1962 & Lys $^{\mathrm{E} 7}$ & $1965^{e}(56)$ & $1956^{e}(44)$ & & $1961^{e}$ \\
\hline $\operatorname{Arg}^{\mathrm{E} 7}$ & $1957(30)$ & $1944(34)$ & $1940(36)$ & 1946 & $\operatorname{Arg}^{\mathrm{E} 7}$ & $1958^{e}(100)$ & & & $1958^{e}$ \\
\hline \multicolumn{5}{|c|}{ Leu65 (E11) mutants } & \multicolumn{5}{|c|}{ Val68 (E11) mutants } \\
\hline $\mathrm{Val}^{\mathrm{E} 11}$ & & $1948(100)$ & & 1948 & Leu $^{\mathrm{E} 11}$ & & $1941(75)$ & $1930(25)$ & 1938 \\
\hline$P h e^{E 11}$ & & $1948(100)$ & & 1948 & $P h e^{E 11}$ & & $1945(64)$ & $1932(36)$ & 1940 \\
\hline \multicolumn{5}{|c|}{ Tyr30 (B10) mutants } & \multicolumn{5}{|c|}{ Leu29 (B10) mutants } \\
\hline Gly ${ }^{\mathrm{B} 10}$ & $1966(39)$ & $1949(26)$ & $1927(35)$ & 1948 & Gly ${ }^{\mathrm{B} 10}$ & $f$ & $f$ & $f$ & $f$ \\
\hline $\mathrm{Ala}{ }^{\mathrm{B} 10}$ & $1963(29)$ & $1949(34)$ & $1926(37)$ & 1944 & $\mathrm{Ala}^{\mathrm{B} 10}$ & $1965(6)$ & $1947(51)$ & $1935(43)$ & 1943 \\
\hline $\mathrm{Val}^{\mathrm{B} 10}$ & $1967(3)$ & $1950(41)$ & $1927(56)$ & 1938 & $\mathrm{Val}^{\mathrm{B} 10}$ & $1965(6)$ & $1946(43)$ & $1933(51)$ & 1941 \\
\hline $\mathrm{Leu}^{\mathrm{B} 10}$ & $1973(5)$ & $1951(30)$ & $1928(65)$ & 1937 & $\mathrm{Ile}^{\mathrm{B} 10}$ & 1965 (4) & 1945 & $1932(48)$ & 1940 \\
\hline $\mathrm{Phe}^{\mathrm{B} 10}$ & 1960 (13) & $1951(44)$ & $1923(43)$ & 1940 & $P h e^{B 10}$ & & & $1932(100)$ & 1932 \\
\hline $\operatorname{Trp}^{\mathrm{B} 10}$ & $1961(52)$ & 1948 (39) & 1925 (9) & 1953 & $\operatorname{Trp}^{\mathrm{B} 10}$ & $1956(37)$ & $1945(63)$ & & 1949 \\
\hline $\operatorname{Arg}^{B 10}$ & $1965(75)$ & $1948(17)$ & $1929(8)$ & 1958 & $\operatorname{Arg}^{B 10}$ & $f$ & $f$ & 100 & $f$ \\
\hline double mutant & & & & & $\mathrm{Tyr}^{\mathrm{B} 10}$ & $1981^{e}(31)$ & $1969^{e}(39)$ & $1931^{e}(30)$ & $1961^{e}$ \\
\hline \multirow{2}{*}{$\mathrm{Leu}^{\mathrm{B} 10} \mathrm{Ala}{ }^{\mathrm{E} 7}$} & $1965(100)$ & & & 1965 & double mutants & & & $1934^{e}(100)$ & $1934^{e}$ \\
\hline & (100) & & & 1700 & $\mathrm{Tyr}^{\mathrm{B} 10} \mathrm{Leu}^{\mathrm{E} 7}$ & $1968^{e}(14)$ & & $1936^{e}(86)$ & $1940^{e}$ \\
\hline
\end{tabular}

${ }^{a}$ Data taken from Li et al. (18) unless mentioned otherwise. ${ }^{b}$ The frequency of the IR band was determined by the peak position, with estimated experimental error $\pm 1 \mathrm{~cm}^{-1}$; the intensity of the IR band was determined by the peak height and was normalized to the strongest band with estimated experimental error $\pm 10 \%$. ${ }^{c}$ The value of $v_{\mathrm{CO}}$ is a weighted measurement of the IR CO spectral components, as computed by $v_{\mathrm{CO}}=\Sigma f_{\mathrm{i}} v_{i}$, where $f_{\mathrm{i}}$ is the fraction of intensity measured by peak height and $v_{i}$ is the peak frequency of spectral component $i$. ${ }^{d}$ Four conformers were tentatively assumed in Lba for comparison with Mb. ${ }^{e}$ Measured by the authors. ${ }^{f}$ Data not available.

Table 1). These peaks are similar to those observed for $\mathrm{CO}-$ heme complexes within a completely apolar binding pocket and imply that $\mathrm{Tyr}^{\mathrm{B} 10}$ makes no significant direct contribution to the electrostatic environment of the bound ligand. In the wild-type metLba structure (4), the $\mathrm{Tyr}^{\mathrm{B} 10}$ side chain is too far away from the iron atom to hydrogen bond directly with bound ligands without significant movements of the $\mathrm{B}$ and E helices (Figure 2). This conclusion is supported by the close similarity of the $v_{\mathrm{CO}}$ bands observed for the Phe ${ }^{\mathrm{E} 7}$, $\mathrm{Leu}^{\mathrm{E} 7}$, and $\mathrm{Val}^{\mathrm{E} 7}$ mutants, which contain $\mathrm{Tyr}^{\mathrm{B} 10}$, and the $v_{\mathrm{CO}}$ band at $1965 \mathrm{~cm}^{-1}$ seen in the completely apolar Leu ${ }^{\mathrm{B} 10}$ $\mathrm{Ala}^{\mathrm{E} 7}$ double mutant of Lba (Figure 4; Table 1). Conversely, $\mathrm{Leu}^{\mathrm{B} 10}$ (which still contains His ${ }^{\mathrm{E} 7}$ ) shows an IR band at much lower frequency, indicating that a strong hydrogen bond can be formed between bound $\mathrm{CO}$ and the distal His in the absence of the Tyr side chain (Figure 4).

Water molecules in the exposed distal pockets of Gly ${ }^{\mathrm{E} 7}$ and $\mathrm{Ala}^{\mathrm{E} 7} \mathrm{MbCO}$ broaden the observed $\nu_{\mathrm{CO}}$ peaks $(18,19)$, and a similar explanation probably accounts for the heterogeneity observed in the IR spectra of $\mathrm{Gly}^{\mathrm{E} 7}$ and $\mathrm{Ala}{ }^{\mathrm{E} 7} \mathrm{LbaCO}$ (Figure 3). The spectrum of $\mathrm{Gly}^{\mathrm{E} 7} \mathrm{LbaCO}$ is unusually broad, with two obvious shoulders at 1952 and $1961 \mathrm{~cm}^{-1}$ (Table 1). The $\mathrm{Ala}^{\mathrm{E} 7} \mathrm{LbaCO}$ spectrum has two distinct peaks. The narrow band at $1969 \mathrm{~cm}^{-1}$ indicates a conformation with a completely apolar environment near bound CO. The broad band centered at $\sim 1951 \mathrm{~cm}^{-1}$ ( similar to that seen in Gly ${ }^{\mathrm{E} 7}$ ) indicates favorable hydrogen-bonding interactions, presumably with distal pocket water molecules. This interpretation is supported by the IR spectrum of the $\mathrm{Leu}^{\mathrm{B} 10} \mathrm{Ala}^{\mathrm{E} 7} \mathrm{LbaCO}$ double mutant, which has no polar residues or stabilized water molecules and shows a single narrow band centered at $v_{\mathrm{CO}}=1965 \mathrm{~cm}^{-1}$ (Figure 4; Table 1). The lack of any

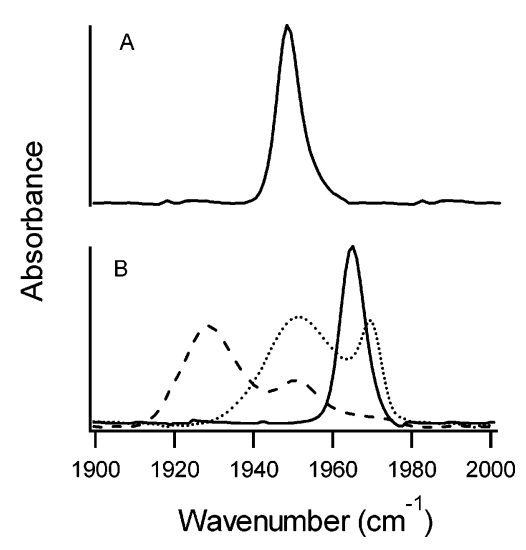

FIGURE 4: Comparison of the IR spectra of (A) wild-type LbaCO and (B) B10/E7 mutants of LbaCO. When $\mathrm{Tyr}^{\mathrm{B}} 10$ is replaced with Leu $\left(\mathrm{Leu}^{\mathrm{B} 10}, \mathrm{-}^{-}-\right)$, a major band at a very low frequency is observed. $\mathrm{Ala}^{\mathrm{E} 7} \mathrm{LbaCO}(\cdots)$ shows a broad band at the "normal" frequency and another narrow band at high frequency. In contrast, the double mutant $\left(\mathrm{Leu}^{\mathrm{B} 10} \mathrm{Ala}{ }^{\mathrm{E} 7},-\right)$, from which both of the polar side chains have been removed, shows only a single narrow band at high frequency (Table 1).

hydrogen-bonding interactions in the double mutant is also apparent from its much larger rate constant for $\mathrm{O}_{2}$ dissociation $\left(k_{\mathrm{O} 2} \approx 100 \mathrm{~s}^{-1}\right)$ compared to those for wild-type $\mathrm{LbaO}_{2}$ $\left(k_{\mathrm{O} 2} \approx 6 \mathrm{~s}^{-1}\right)$ and the two corresponding single mutants $\left(k_{\mathrm{O} 2}\right.$ $\approx 1-3 \mathrm{~s}^{-1}$ ) (Table 2). Thus, although $\mathrm{His}^{\mathrm{E} 7}$ is the main source of polarity around bound ligands in Lba, hydrogen bonding is relatively weak, and $\mathrm{Tyr}^{\mathrm{B} 10}$ can have a significant indirect influence. This results in differences in the electrostatic interactions with bound ligands in the distal heme pockets of Lba and $\mathrm{Mb}$. 


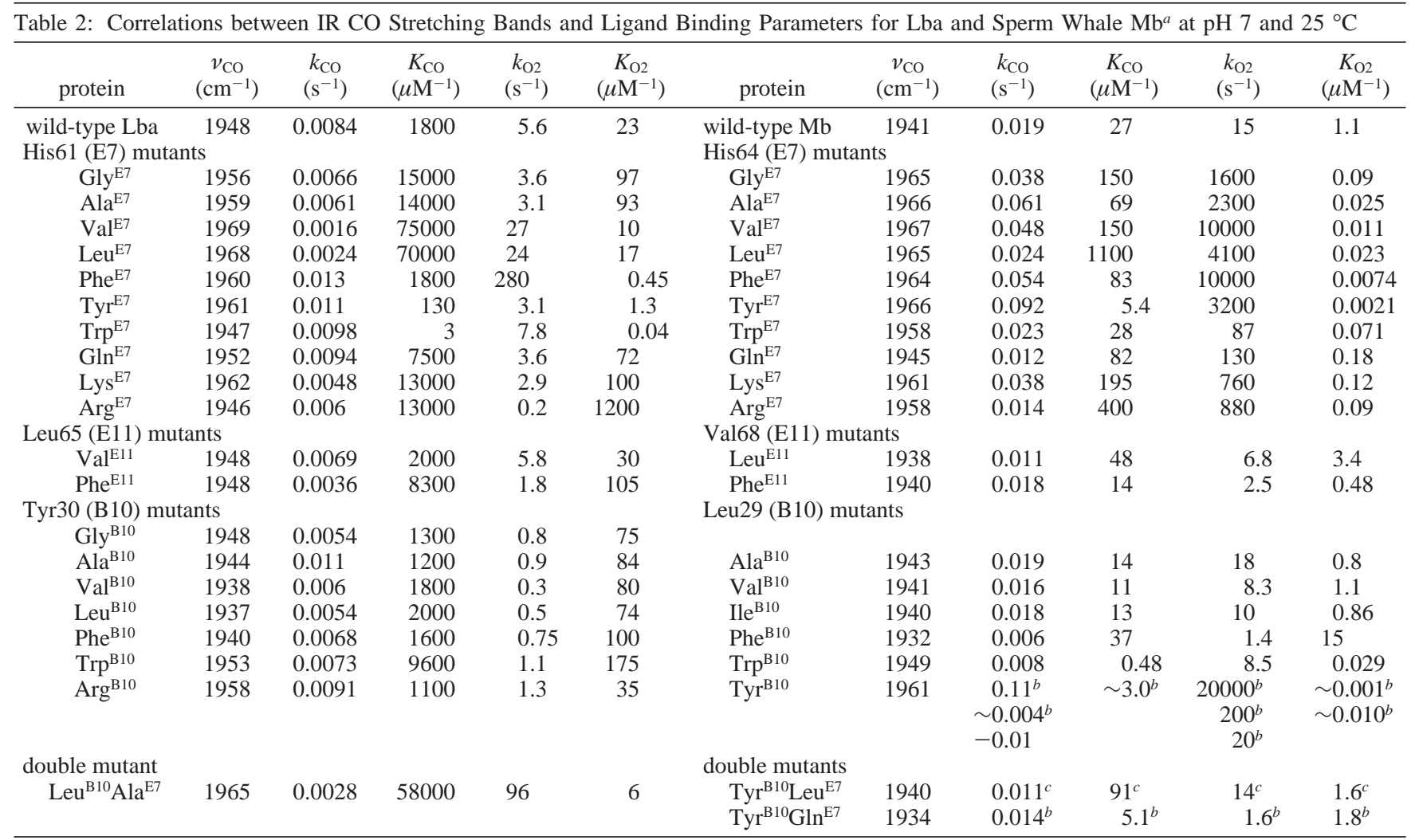

${ }^{a}$ Data taken from Li et al. (18) and Kundu et al. (5). ${ }^{b}$ Data from Draghi et al. (13). ${ }^{c}$ Measured by the authors.

Role of the B10 Side Chain in Positioning His ${ }^{E 7}$ in $\mathrm{Mb}$ and Lba. An important difference between Lba and $\mathrm{Mb}$ is the Tyr found at the B10 helical position in the former instead of an apolar Leu in the latter (Figure 2). Replacement of $\mathrm{Tyr}^{\mathrm{B} 10}$ in $\mathrm{LbaCO}$ by any other amino acid, irrespective of size or polarity, results in the appearance of multiple $v_{\mathrm{CO}}$ peaks (Figure 5; Table 1). In general, the IR spectra of the B10 mutants are mixtures of high- and low-frequency bands, which are completely absent in wild-type LbaCO. The lowfrequency $v_{\mathrm{CO}}$ peaks for the $\mathrm{B} 10 \mathrm{LbaCO}$ mutants are at $\sim 1926 \mathrm{~cm}^{-1}$, which is significantly lower than those seen in the B10 mutants of sperm whale $\mathrm{MbCO}\left(\sim 1932 \mathrm{~cm}^{-1}\right.$, Figure 5; Table 1). The low-frequency peaks in the Lba B10 mutants must be due to conformations in which the distal His forms a much stronger hydrogen bond with bound $\mathrm{CO}$ than that in the native protein. This interpretation in terms of more favorable electrostatic interactions is supported by the uniform decrease in the rate constant for $\mathrm{O}_{2}$ dissociation from all of the $\mathrm{B} 10$ mutants compared to wild-type $\mathrm{LbaO}_{2}$ (Table 2).

The average $v_{\mathrm{CO}}$ for the apolar $\mathrm{B} 10 \mathrm{LbaCO}$ mutants is lower than that of wild-type LbaCO (Table 1). However, there are also bands in the $1960-1970 \mathrm{~cm}^{-1}$ range, indicating conformations with completely apolar binding sites and no interaction with the distal His. Thus, when $\mathrm{Tyr}^{\mathrm{B} 10}$ in Lba is replaced by other amino acids, the side chain of $\mathrm{His}^{\mathrm{E} 7}$ adopts multiple orientations, some of which involve formation of strong hydrogen bonds with bound ligands and some of which involve no interaction at all. In contrast, apolar B10 mutations in $\mathrm{Mb}$ only enhance the low-frequency band associated with the $\mathrm{A}_{3}$ conformer $\left(v_{\mathrm{CO}} \approx 1932 \mathrm{~cm}^{-1}\right)$. Little or no intensity associated with high-frequency bands at $v_{\mathrm{CO}}$ $=1960-1970 \mathrm{~cm}^{-1}$ is seen (Figure 5; Table 1). The IR spectrum of $\mathrm{Phe} \mathrm{B}^{\mathrm{B} 10} \mathrm{MbCO}$ has a single band at $1932 \mathrm{~cm}^{-1}$. The crystal structures of $\mathrm{Phe}^{\mathrm{B} 10} \mathrm{MbCO}$ and $\mathrm{MbO}_{2}$ show that $\mathrm{His}^{\mathrm{E} 7}$ is fixed in a more $\mathrm{A}_{3}$-like conformation and the positive edge of the benzyl side chain points toward the bound ligand (18). This conformation causes a $\sim 10$-fold decrease in the rate of $\mathrm{O}_{2}$ dissociation from $\mathrm{Phe}^{\mathrm{B} 10} \mathrm{MbO}_{2}$ compared to that from the wild-type protein (Table 2; 43).

The $\operatorname{Trp}^{\mathrm{B} 10}$ mutations in both $\mathrm{LbaCO}$ and $\mathrm{MbCO}$ cause a shift in $\bar{\nu}_{\mathrm{C}-\mathrm{O}}$ to higher frequencies, and there is minimal appearance of strong low-frequency bands in the 1920-1935 $\mathrm{cm}^{-1}$ region (Table 1). In these cases, the large size of the indole ring appears to be "pushing" the distal His away from bound ligands. The $\mathrm{Arg}^{\mathrm{B} 10}$ mutation in $\mathrm{LbaCO}$ causes a more significant effect, increasing $\bar{v}_{\mathrm{C}-\mathrm{O}}$ from 1948 to $1958 \mathrm{~cm}^{-1}$, suggesting that the $\mathrm{His}^{\mathrm{E} 7}$ side chain has been pushed out into the solvent. Because the B10 side chain in Lba is too far from the active site, the guanidino group of $\mathrm{Arg}^{\mathrm{B} 10}$ cannot access the bound ligands either to interact favorably with them (Figure 2).

The $\mathrm{Tyr}^{\mathrm{B} 10}$ mutation produces the largest effect on the IR spectrum of $\mathrm{MbCO}$, causing the appearance of multiple bands from 1931 to $1980 \mathrm{~cm}^{-1}$ (Figure 5). Thus, a Tyr side chain at the B10 position in $\mathrm{Mb}$ has the opposite effect of that observed in Lba. The phenolic side chain in Mb causes multiple conformations with positive and negative fields adjacent to the bound ligand. This interpretation is supported by the multiple phases seen for $\mathrm{O}_{2}$ dissociation from $\mathrm{Tyr}^{\mathrm{B} 10}$ $\mathrm{MbO}_{2}$ (13; Table 2). In contrast, the $\mathrm{Tyr}^{\mathrm{B} 10}$ side chain in native Lba "traps" $\mathrm{His}^{\mathrm{E} 7}$ in a single conformational state, which can only donate a weak hydrogen bond to bound ligands. When $\mathrm{Tyr}^{\mathrm{B} 10}$ is replaced by Leu in $\mathrm{LbaCO}$ (a distal pocket akin to $\mathrm{Mb}$ ), $\mathrm{His}^{\mathrm{E} 7}$ is able to adopt a conformation with a much stronger hydrogen bond to bound ligands as 


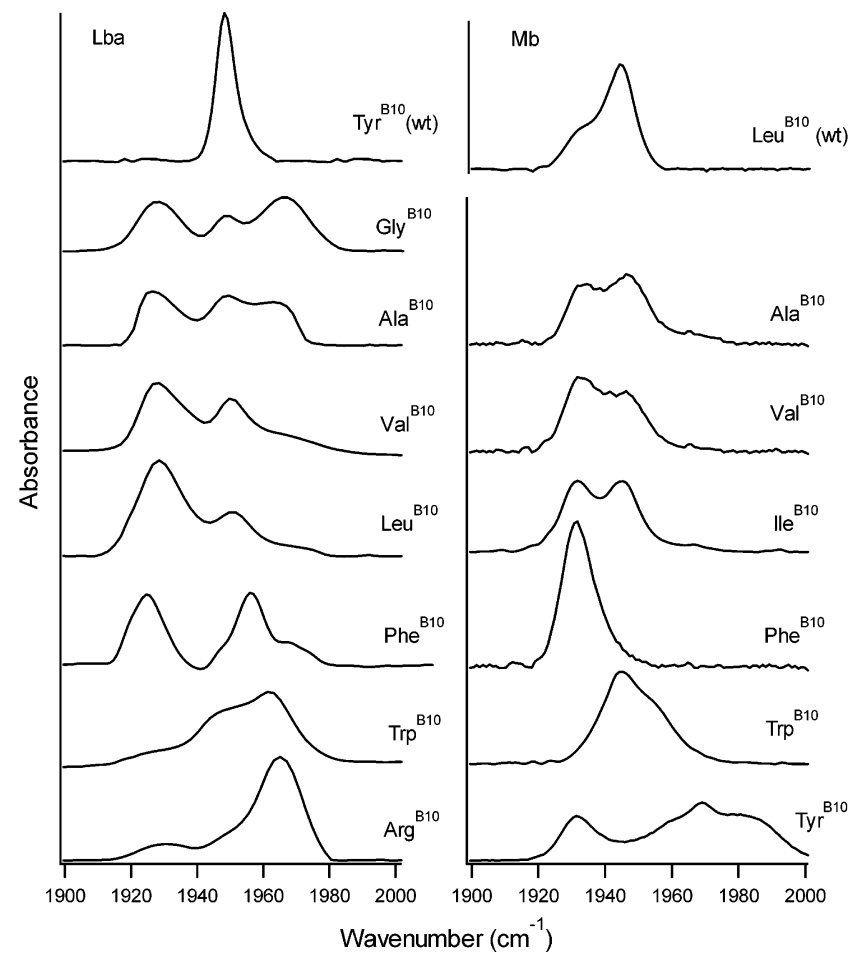

FIGURE 5: IR spectra of B10 mutants of soybean LbaCO and sperm whale MbCO. All of the Lba mutants show multiple peaks, including at least one low-frequency band. Most of the B10 mutations in $\mathrm{Mb}$ change only in the proportion of the $v_{1}$ versus $v_{3}$ bands, with $\mathrm{Phe} \mathrm{B}^{\mathrm{B} 10} \mathrm{MbCO}$ showing only a single conformer at $v_{3}$ $=1932 \mathrm{~cm}^{-1}$. In contrast, the $\mathrm{Tyr}^{\mathrm{B} 10}$ mutation in $\mathrm{MbCO}$ causes the appearance of a major high-frequency band at $1969 \mathrm{~cm}^{-1}$. The spectra for the Ala, Val, Ile, and Phe B10 Mb mutant proteins were taken from Li et al. (18); the other spectra were measured in this work.

seen by the appearance of a major $v_{\mathrm{CO}}$ band at $1926 \mathrm{~cm}^{-1}$ (Figure 5). This conclusion is supported by the 10-fold drop in the rate of $\mathrm{O}_{2}$ dissociation from the same Lba mutant (Table 2).

Polar Mutations at the E7 Position. As shown in Figure 6 , the native $\mathrm{Tyr}^{\mathrm{B} 10}$ side chain in Lba also affects the position of polar amino acids when they are inserted into the E7 helical position as compared to their positions in analogous E7 mutants of $\mathrm{Mb}$. The most dramatic differences between the two proteins are observed for the single $\operatorname{Arg}^{\mathrm{E} 7}$ mutants. In $\mathrm{Arg}^{\mathrm{E} 7} \mathrm{MbCO}$, a single, narrow high-frequency band at $1958 \mathrm{~cm}^{-1}$ is observed (Figure 6) and has been interpreted in terms of the $\mathrm{Arg}^{\mathrm{E} 7}$ guanidino group pointing into the solvent, as has been observed in $\mathrm{Hb}$ Zurich $\left(\beta\right.$ His $\left.^{\mathrm{E} 7} \rightarrow \operatorname{Arg}\right)$ (44-47). In contrast, several bands are observed for $\operatorname{Arg}^{\mathrm{E} 7}$ LbaCO (Table 1). The majority of the conformers occur at relatively low frequencies in the $1940-1945 \mathrm{~cm}^{-1}$ region (Figure 6), indicating a positive electrostatic field adjacent to bound CO. More remarkably, the $\mathrm{His}^{\mathrm{E} 7} \rightarrow \mathrm{Arg}$ mutation in Lba causes the rate constant for $\mathrm{O}_{2}$ dissociation to decrease by $\sim 30$-fold, indicating that an even stronger stabilizing interaction occurs when dioxygen is bound (Table 2). In contrast, the $\mathrm{His}^{\mathrm{E} 7} \rightarrow \mathrm{Arg}$ mutation in $\mathrm{Mb}$ causes $k_{\mathrm{O} 2}$ to increase from 15 to $\sim 1000 \mathrm{~s}^{-1}$, indicating the loss of stabilizing electrostatic or hydrogen-bonding interactions.

Taken together, these spectroscopic and ligand-binding data suggest that the guanidino group of $\mathrm{Arg}^{\mathrm{E} 7}$ can remain in the distal pocket of Lba. In the CO complex, the side chain adopts multiple conformations. The guanidino group

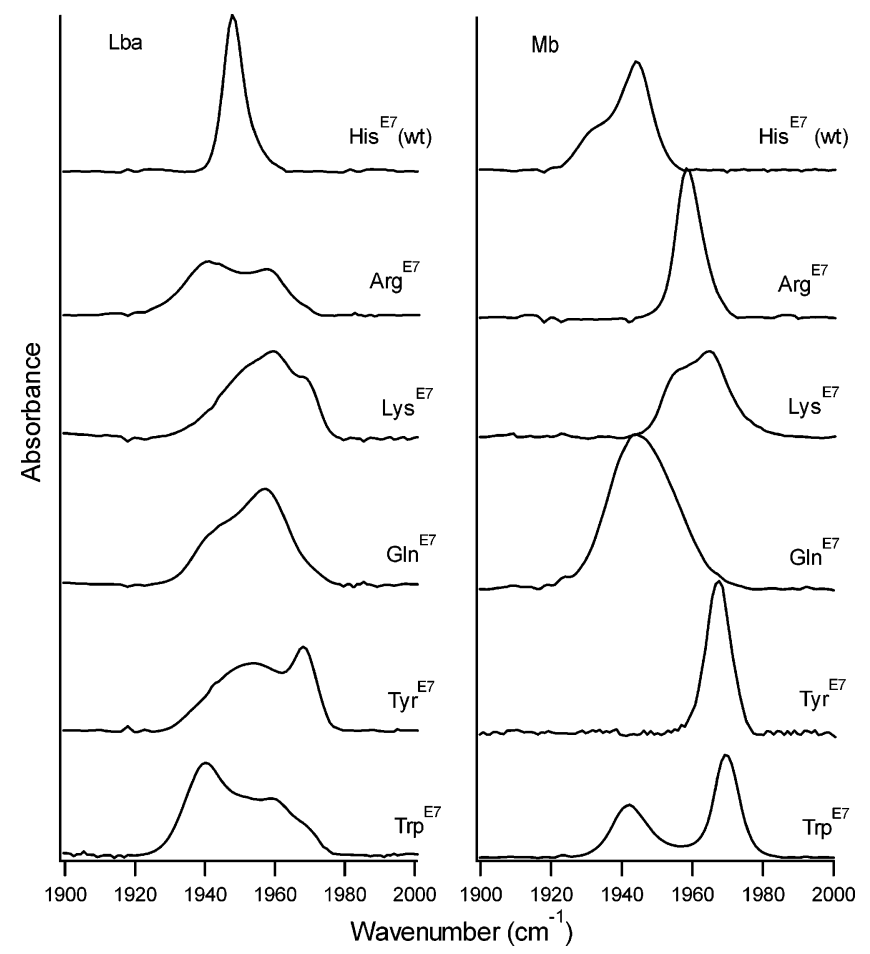

FIGURE 6: IR spectra of $\mathrm{LbaCO}$ and $\mathrm{MbCO}$ mutants with charged or polar residues at position E7. Arg ${ }^{\mathrm{E} 7} \mathrm{MbCO}$ shows a single, highfrequency peak indicating that this residue does not interact with bound $\mathrm{CO}$. In contrast, $\mathrm{Arg}^{\mathrm{E} 7} \mathrm{LbaCO}$ shows multiple bands with significant populations of conformers having lower $v_{\mathrm{CO}}$, suggesting that this side chain can form hydrogen bonds with bound CO. The $\mathrm{Lys}^{\mathrm{E7}}$ mutants for both, however, are predominantly in conformations with higher $v_{\mathrm{CO}}$ and possibly have their side chains swinging out of the distal heme pocket. Gln ${ }^{\mathrm{E} 7} \mathrm{MbCO}$ and $\mathrm{LbaCO}$ show peak positions similar to those of the wild-type proteins, but the bands are broader. $\mathrm{Tyr}^{\mathrm{E} 7}$ in $\mathrm{MbCO}$ exclusively provides an apolar environment to bound $\mathrm{CO}$, whereas $\mathrm{Tyr}^{\mathrm{E} 7}$ in $\mathrm{LbaCO}$ provides some positive potential as well. $\operatorname{Trp}^{\mathrm{E} 7} \mathrm{MbCO}$ and $\mathrm{LbaCO}$ show a conformer with lower $v_{\mathrm{CO}}$ in addition to a higher one. The spectra for $\mathrm{Arg}^{\mathrm{E} 7}$ and $\mathrm{Lys}^{\mathrm{E} 7} \mathrm{MbCO}$ mutant proteins were measured for this work, and the others were taken from Li et al. (18).

can either swing out into solvent, causing an apolar active site and an increase in $v_{\mathrm{CO}}$, or remain in the pocket, causing an increase in the electrostatic field near the bound ligand and a decrease in $v_{\mathrm{CO}}$. The latter "in" conformation appears to be the dominant one when $\operatorname{Arg}^{\mathrm{E} 7} \mathrm{Lba}$ binds $\mathrm{O}_{2}$, as judged by the dramatic decrease in $k_{\mathrm{O} 2}$ (Table 2). The $\mathrm{Tyr}^{\mathrm{B} 10}$ hydroxyl $\mathrm{O}$ atom probably helps to stabilize the "in" conformation by acting as a hydrogen bond acceptor for the guanidino group, and the partial negative charge on bound $\mathrm{O}_{2}$ provides additional electrostatic stabilization. In $\mathrm{Mb}$, the naturally occurring $\mathrm{Leu}^{\mathrm{B} 10}$ side chain cannot facilitate internalization of the $\mathrm{Arg}^{\mathrm{E} 7}$ side chain, and the free energy released by solvation of the guandino group out-competes any weak, favorable interaction with bound ligands. In addition, the size of the distal pocket in $\mathrm{Mb}$ is smaller and probably cannot easily accommodate the large $\operatorname{Arg}^{\mathrm{E} 7}$ side chain.

The effects of the $\mathrm{His}^{\mathrm{E} 7} \rightarrow \mathrm{Lys}^{\mathrm{E} 7}$ mutation on the IR spectra of $\mathrm{MbCO}$ and $\mathrm{LbaCO}$ are much more similar than in the case of the $\mathrm{Arg}^{\mathrm{E}}$ replacement (Figure 6). In both proteins, most of the absorbance occurs at higher frequencies, indicating that the dominant conformations have the primary amine pointing out of the pocket, increasing the apolar character of the ligand binding site. The Gln ${ }^{\mathrm{E} 7}$ mutations in both proteins cause little change in the average $v_{\mathrm{CO}}$ value but do 


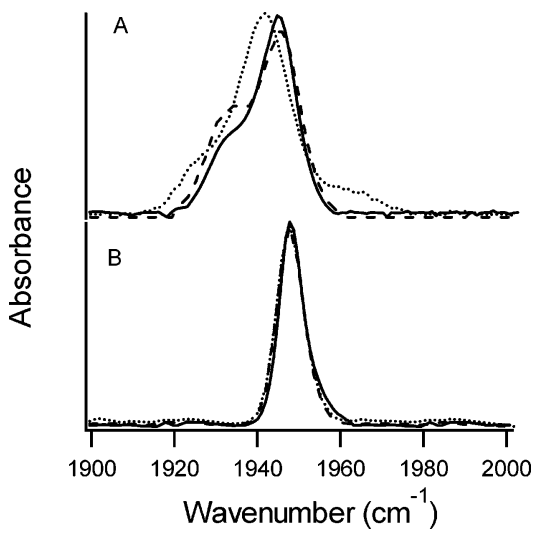

FIGURE 7: IR spectra of position E11 mutants of (A) sperm whale $\mathrm{MbCO}$ and (B) soybean LbaCO. Spectra for the wild-type proteins are shown as solid lines. When $\mathrm{Val}^{\mathrm{E} 11}$ is replaced with Leu $(\cdots)$ or Phe (- - ) in $\mathrm{Mb}$, the resulting IR spectra of mutant proteins are different from the wild-type MbCO spectrum. When $\mathrm{Leu}^{\mathrm{E} 11}$ in LbaCO is replaced with Val (*) and Phe (- - ), there is no change in the measured IR spectrum. The spectra for the MbCO mutants were taken from $\mathrm{Li}$ et al. (18).

broaden the major bands, presumably due to the flexible nature of the amide side chain and the potential for electrostatic interactions with either the carbonyl $\mathrm{O}$ atom or the amide protons.

The $\mathrm{Tyr}^{\mathrm{E}}{ }^{\mathrm{7}}$ substitutions cause shifts to higher frequencies in both proteins, suggesting that either the phenolic side chain moves out of the active site or that the nonbonded electrons of the phenoxyl $\mathrm{O}$ atom are pointed toward the bound ligand. In $\mathrm{MbCO}$, the former interpretation probably applies because a single, narrow band is observed at $1966 \mathrm{~cm}^{-1}$. In $\mathrm{LbaCO}$, a narrow band is observed at $1968 \mathrm{~cm}^{-1}$, but a large, broad band also occurs around $1950 \mathrm{~cm}^{-1}$ and is similar to that seen for the $\mathrm{Ala}^{\mathrm{E} 7} \mathrm{LbaCO}$ complex. The $\operatorname{Trp}^{\mathrm{E} 7}$ mutant proteins of Lba and $\mathrm{Mb}$ show two principal conformers. The dominant conformer in $\mathrm{LbaCO}$ has a low-frequency band at $v_{\mathrm{CO}}=1939 \mathrm{~cm}^{-1}$, whereas the dominant conformer in $\mathrm{MbCO}$ has a high-frequency band at $1969 \mathrm{~cm}^{-1}$ (Figure 6; Table 1). The indole $\mathrm{N}-\mathrm{H}$ group or the positive edge of the aromatic multipole of $\operatorname{Trp}^{\mathrm{E} 7}$ probably interacts with bound $\mathrm{CO}$ in the low-frequency conformers of both proteins, resulting in the appearance of bands in the $1940 \mathrm{~cm}^{-1}$ region (18).

Leu ${ }^{E 11}$ in Lba Has Little Effect on Hydrogen Bonding. $\mathrm{Val}^{\mathrm{E} 11}$ in $\mathrm{Mb}$ is important for maintaining the appropriate distal pocket volume for ligand binding and prevention of autoxidation (47), and mutations at this position have been found to influence the MbCO IR spectra significantly (18, 19, 47-49). As seen in Figure 7A and Table 1, even relatively subtle mutations at the E11 position in $\mathrm{Mb}$ affect its IR spectrum. However, the corresponding Lba mutant proteins leave the IR spectra completely unaltered (Figure 7B). Apolar replacement of Leu ${ }^{\mathrm{E} 11}$ in Lba also has only small, subtle effects on protein stability and ligand-binding kinetics (5). The crystal structure of Lba shows that the naturally occurring Leu ${ }^{\mathrm{E} 11}$ side chain is behind the distal His, almost on the far interior side of the ligand-binding site compared to the position of $\mathrm{Val}^{\mathrm{E} 11}$ in $\mathrm{Mb}$ (4). Therefore, the importance of this amino acid in $\mathrm{Mb}$ is not shared in the distal pocket of Lba.

Role of the B10 Amino Acid in Other Leghemoglobins. Tyr is not conserved at position B10 in all leghemoglobins.

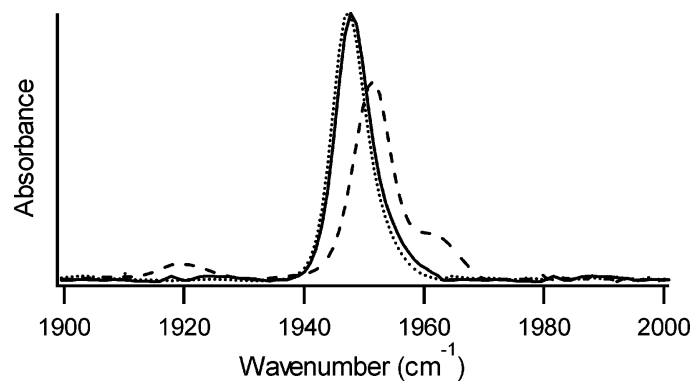

FIGURE 8: IR spectra of the CO complexes of leghemoglobins from different species of plants. Both cowpea $(\cdots)$ and soybean $(-)$ Lb have a His ${ }^{\mathrm{E}}-\mathrm{Tyr}^{\mathrm{B} 10}$ distal pair and identical IR spectra. Lupin (- - -) $\mathrm{Lb}$ has a His ${ }^{\mathrm{E} 7}-\mathrm{Phe}^{\mathrm{B} 10}$ distal pair and shows a different IR spectrum with additional minor low- and high-frequency peaks.

Table 3: IR CO Stretching Bands for Three Leghemoglobins at $\mathrm{pH}$ 7 and $25{ }^{\circ} \mathrm{C}$

\begin{tabular}{lcccccc}
\hline \multicolumn{1}{c}{ protein } & $\begin{array}{c}v_{0}{ }^{a}(\%) \\
\left(\mathrm{cm}^{-1}\right)\end{array}$ & $\begin{array}{c}v_{1,2}(\%) \\
\left(\mathrm{cm}^{-1}\right)\end{array}$ & $\begin{array}{c}v_{3}(\%) \\
\left(\mathrm{cm}^{-1}\right)\end{array}$ & $\begin{array}{c}v_{\mathrm{CO}}{ }^{b} \\
\left(\mathrm{~cm}^{-1}\right)\end{array}$ & $\begin{array}{c}k_{\mathrm{CO}} \\
\left(\mathrm{s}^{-1}\right)\end{array}$ & $\begin{array}{c}k_{\mathrm{O} 2} \\
\left(\mathrm{~s}^{-1}\right)\end{array}$ \\
\hline soybean Lba & & $1948(100)$ & & 1948 & 0.0084 & 5.6 \\
cowpea LbII & & $1947(100)$ & & 1947 & $0.01^{c}$ & $5.5^{c}$ \\
lupin LbI & $1962(18)$ & $1951(75)$ & $1919(7)$ & 1951 & $0.014^{c}$ & $20^{c}$ \\
\hline
\end{tabular}

${ }^{a, b}$ See footnotes $b$ and $c$ of Table 1. ${ }^{c}$ Data taken from Gibson et al. (51).

Other species, most notably lupin, contain Phe at this site (50). To examine the importance of this naturally occurring $\mathrm{Tyr} \longrightarrow$ Phe replacement, IR spectra for cowpea LbII $\left(\mathrm{Tyr}^{\mathrm{B} 10}\right)$ and lupin LbI $\left(\mathrm{Phe}^{\mathrm{B} 10}\right)$ were measured (Figure 8). Cowpea LbII has an IR spectrum identical to that of soybean Lba, with a single conformer at $1948 \mathrm{~cm}^{-1}$ (Table 3). Both of these Lbs have a distal $\mathrm{His}^{\mathrm{E} 7}-\mathrm{Tyr}^{\mathrm{B} 10}$ pair, nearly identical rate constants for oxygen binding (Table 3) (51), and presumably similar mechanisms for regulating ligand binding.

As shown in Figure 5, replacing $\mathrm{Tyr}^{\mathrm{B} 10}$ with Phe causes profound changes in the IR spectrum of soybean LbaCO, leading to the appearance of a large low-frequency band centered at $1923 \mathrm{~cm}^{-1}$ and the retention of a peak at 1950 $\mathrm{cm}^{-1}$. The IR spectrum of lupin LbICO is different from those of both native soybean Lba and its $\mathrm{Phe}^{\mathrm{B} 10}$ mutant. However, a major band $(\sim 75 \%)$ is observed at $1951 \mathrm{~cm}^{-1}$, which is similar in position to that for cowpea and soybean LbCO. Thus, in lupin LbICO there must be constraints other than $\mathrm{Tyr}^{\mathrm{B} 10}$ that position $\mathrm{His}^{\mathrm{E} 7}$ in a conformation that allows only weak hydrogen bonding to bound $\mathrm{CO}$. Harutyunyan et al. (52) have suggested that the $\mathrm{His}^{\mathrm{E} 7}$ side chain in the lupin LbICO crystal structure appears to be fixed in position by a lattice of hydrogen bonds linking $\mathrm{N} \delta$ of the imidazole side chain to well-defined water molecules, $\mathrm{Glu}^{\mathrm{E} 3}$, and one of the heme propionates. However, these constraints do not appear to be as strong as those imposed by $\mathrm{Tyr}^{\mathrm{B} 10}$ in the other Lbs, because lupin LbICO also shows minor low- (7\%) and high-frequency (18\%) bands at 1920 and $1962 \mathrm{~cm}^{-1}$, respectively (Table 3 ).

The Tyr ${ }^{B 10}-$ His $^{E 7}$ Combination Destabilizes Bound Ligands. The side chain at the $\mathrm{B} 10$ position in $\mathrm{Mb}$ is close enough to make direct contact with bound ligands. However, multiple $v_{\mathrm{CO}}$ bands and heterogeneous ligand binding are observed for the single $\mathrm{Tyr}^{\mathrm{B} 10} \mathrm{Mb}$ mutant, and there is a net increase in $\bar{v}_{\mathrm{CO}}$ and the average value of $k_{\mathrm{O} 2}$ (Table 2; Figure 9A). Draghi et al. (13) have proposed that $\mathrm{Try}^{\mathrm{B} 10}$ and $\mathrm{His}^{\mathrm{E}}{ }^{\mathrm{Z}}$ 


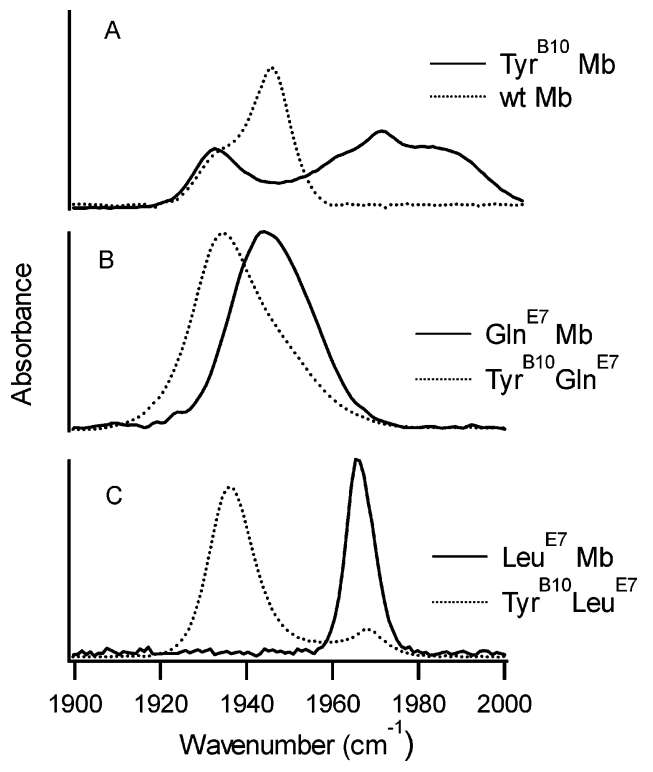

FIGURE 9: IR spectra of sperm whale MbCO mutants with Tyr at position B10. (A) IR spectra for wild-type $\operatorname{MbCO}(\cdots)$ and for the $\mathrm{Tyr}^{\mathrm{B} 10}$ single mutant (-), which shows a major high-frequency band, suggesting that $\mathrm{Tyr}^{\mathrm{B} 10}$ prevents $\mathrm{His}^{\mathrm{E} 7}$ from stabilizing bound $\mathrm{CO}$. In contrast, major low-frequency bands are observed for $\mathrm{MbCO}$ mutants containing the combination of (B) $\mathrm{Tyr}^{\mathrm{B} 10}$ and $\mathrm{Gln}^{\mathrm{E} 7}(\cdots)$ or (C) $\mathrm{Tyr}^{\mathrm{B} 10}$ and $\mathrm{Leu}^{\mathrm{E} 7}(\cdots)$. The corresponding single-mutants $\mathrm{Gln}^{\mathrm{E} 7}$ and $\mathrm{Leu}^{\mathrm{E} 7}$ show peaks at much higher frequencies. The results in panels $\mathrm{B}$ and $\mathrm{C}$ show that $\mathrm{Tyr}^{\mathrm{B} 10}$ can hydrogen bond directly to bound $\mathrm{CO}$ in the absence of His ${ }^{\mathrm{E}}$.

sterically "clash" so that neither side chain can easily hydrogen bond to bound ligands. Replacement of the distal His with Gln allows the phenol side chain to interact favorably and directly with bound ligands in the $\mathrm{Tyr}^{\mathrm{B} 10} \mathrm{Gln}^{\mathrm{E} 7}$ Mb double mutant (Figure 9B; Table 2; 13 and references therein). When $\mathrm{His}^{\mathrm{E}}{ }^{\mathrm{7}}$ is replaced with Leu in $\mathrm{Tyr}^{\mathrm{B} 10} \mathrm{MbCO}$, a major (86\%) low-frequency band appears at $1936 \mathrm{~cm}^{-1}$ (Figure 9C), and the value of $k_{\mathrm{O} 2}$ for the $\mathrm{Tyr}^{\mathrm{B} 10} \mathrm{Leu}^{\mathrm{E} 7}$ double mutant is markedly decreased compared to the corresponding rate constants for the single E7 or B10 Mb mutants (Table $2 ; 13)$. Thus, in the absence of a distal His, $\mathrm{Tyr}^{\mathrm{B} 10}$ can interact directly and favorably with bound ligands in mammalian Mbs.

A major conclusion from the IR and ligand-binding data in Table 2 is that the $\mathrm{Tyr}^{\mathrm{B} 10}-\mathrm{His}^{\mathrm{E} 7}$ combination weakens hydrogen bonding to bound ligands in both Lba and Mb. In $\mathrm{Mb}$, the two residues clash sterically, causing multiple conformations (IR bands) and kinetic phases (Figures 5 and 9; 13). In Lba, the two residues appear to interact specifically forming a single conformation, as judged by the narrow symmetric CO IR band. As described below, the simplest explanation is that $\mathrm{Tyr}^{\mathrm{B} 10}$ "pulls" $\mathrm{His}^{\mathrm{E} 7}$ slightly away from the bound ligand by forming a hydrogen bond between the phenolic proton and the nonbonded electrons of the $\mathrm{N} \delta$ of His $^{\mathrm{E7}}$ (Figure 10A), an interpretation that is supported by modeling of the crystal structure of acetate-metLba (4) and by high-resolution NMR data $(37,38,53)$.

\section{DISCUSSION}

Structural Model for His ${ }^{E 7}-$ Tyr $^{B 10}$ Interactions in Lba. The experimental evidence in favor of a $\mathrm{Tyr}^{\mathrm{B} 10}-\mathrm{His}^{\mathrm{E} 7}$ interaction in Lba is threefold. (1) Multiple $v_{\mathrm{CO}}$ bands appear when $\mathrm{Tyr}^{\mathrm{B} 10}$ is replaced by almost any other amino acid. These results suggest that in native Lba the phenol side chain holds $\mathrm{His}^{\mathrm{E} 7}$ in a fixed location farther away from bound ligands than the position of $\mathrm{His}^{\mathrm{E}}$ in $\mathrm{Mb}$. In almost all of the Lba B10 mutants, a low-frequency band is observed at $\sim 1925$ $\mathrm{cm}^{-1}$, indicating that a stronger hydrogen bond can form between $\mathrm{His}^{\mathrm{E} 7}$ and bound $\mathrm{CO}$ in the absence of $\mathrm{Tyr}^{\mathrm{B} 10}$. (2) The B10 Lba mutations also cause significant decreases in $k_{\mathrm{O} 2}$, indicating a strengthening of the hydrogen bond to bound $\mathrm{O}_{2}$ when $\mathrm{His}^{\mathrm{E} 7}$ is "freed" from its interaction with the phenol side chain of $\mathrm{Tyr}^{\mathrm{B} 10}$. (3) Replacement of $\mathrm{His}^{\mathrm{E} 7}$ with large aliphatic residues (Val and Leu) causes a $20 \mathrm{~cm}^{-1}$ increase in the peak position of the major $v_{\mathrm{CO}}$ band, indicating loss of hydrogen bonding to bound ligands. However, the increases in the rate constants for $\mathrm{O}_{2}$ dissociation from these $\mathrm{LbaO}_{2}$ mutants are only 5-fold, as compared to the 200-500-fold increases observed for the $\mathrm{Val}^{\mathrm{E} 7}$ and $\mathrm{Leu}^{\mathrm{E} 7}$ replacements in sperm whale $\mathrm{Mb}$. Thus, the hydrogenbonding interaction between bound ligands and $\mathrm{His}^{\mathrm{E} 7}$ in wildtype Lba is significantly weaker than in $\mathrm{Mb}$, presumably due to interactions with $\mathrm{Tyr}^{\mathrm{B} 10}$.

In the absence of crystal structures of $\mathrm{CO}$ and $\mathrm{O}_{2}$ complexes of soybean Lba, structural modeling was used to investigate possible interactions between $\mathrm{Tyr}^{\mathrm{B} 10}$ and $\mathrm{His}^{\mathrm{E} 7}$ that would explain the IR spectra of native and mutant LbaCOs and the rates of $\mathrm{O}_{2}$ dissociation from the corresponding oxygenated complexes. In the crystal structure of acetate-bound soybean metLba, $\mathrm{Tyr}^{\mathrm{B} 10}$ is much closer to $\mathrm{His}^{\mathrm{E} 7}$ than to the heme iron or the first two atoms of the bound ligand (4). The $\mathrm{O}$ atom of the $\mathrm{Tyr}^{\mathrm{B} 10}$ side chain is $\sim 3.3 \AA$ away from the edge of the imidazole ring of His ${ }^{\mathrm{E} 7}$ and $>4.0 \AA$ away from the second ligand atom. Even in the absence of a bound ligand, the phenol side chain cannot move closer to the iron atom unless there is substantial movement of the entire B helix toward the heme plane, and such a largescale movement would also require significant movement of the E helix. However, the $\mathrm{Tyr}^{\mathrm{B} 10}$ and $\mathrm{His}^{\mathrm{E}}{ }^{\mathrm{T}}$ side chains both appear to be flexible enough to interact with each other while allowing only the E7 imidazole to interact directly with bound ligands.

The model shown in Figure 10A was generated from the acetate-bound metLba crystal structure (4) by using the "flipped" orientation of the E7 imidazole ring described by Mabbutt et al. $(37,38)$ and then rotating both the $\mathrm{His}^{\mathrm{E} 7}$ and $\mathrm{Tyr}^{\mathrm{B} 10}$ side chains about their $\mathrm{C} \alpha-\mathrm{C} \beta$ and $\mathrm{C} \beta-\mathrm{C} \gamma$ bonds in the program $\mathrm{O}$ without violating van der Waals restraints. In this conformation, the $\mathrm{N} \delta$ atom of $\mathrm{His}^{\mathrm{E} 7}$ can accept a hydrogen bond from the $\mathrm{OH}$ group of $\mathrm{Tyr}^{\mathrm{B} 10}$, and the $\mathrm{N} \epsilon-\mathrm{H}$ group of His ${ }^{\mathrm{E} 7}$ can still donate a hydrogen bond to the bound ligand. This model predicts one $\mathrm{His}^{\mathrm{E} 7}$ conformer for the $\mathrm{CO}$ complex because only one orientation could be found that allows formation of a strong hydrogen bond between His ${ }^{\mathrm{E} 7}$ and both the $\mathrm{Tyr}^{\mathrm{B} 10}$ side chain and the bound ligand. In support of the model, the IR spectrum of LbaCO shows a single, narrow band with a peak at a slightly higher $v_{\mathrm{CO}}$ than that for $\mathrm{Mb}$. The model is also consistent with multiple $v_{\mathrm{CO}}$ peaks in the IR spectra of $\mathrm{Tyr}^{\mathrm{B} 10}$ mutants of LbaCO because, in the absence of hydrogen bonding to the phenol side chain, $\mathrm{His}^{\mathrm{E} 7}$ is "free" to adopt other orientations.

The model in Figure $10 \mathrm{~A}$ requires a $180^{\circ}$ rotation of the $\mathrm{His}^{\mathrm{E} 7}$ side chain about the $\mathrm{C} \beta-\mathrm{C} \gamma$ bond compared to the orientation reported for the metLba acetate (4) and nicotinate (54) crystal structures. As mentioned previously, this "flipped" 


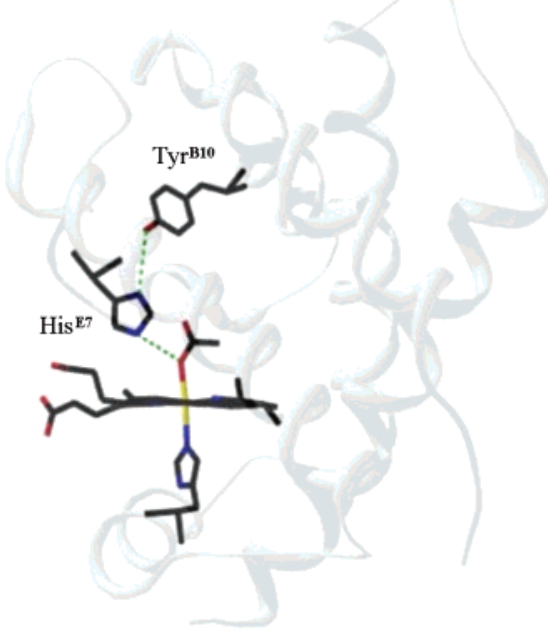

(A) Wild type LbaCO model

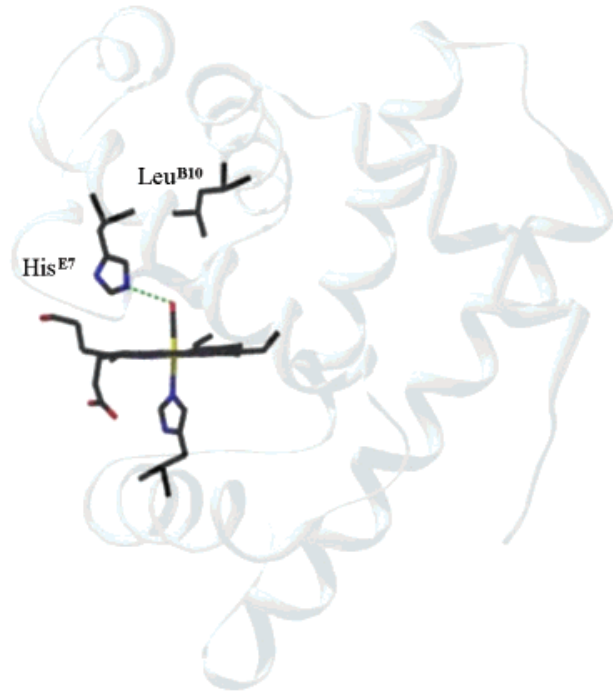

(B) Wild type $\mathrm{MbCO}$ structure

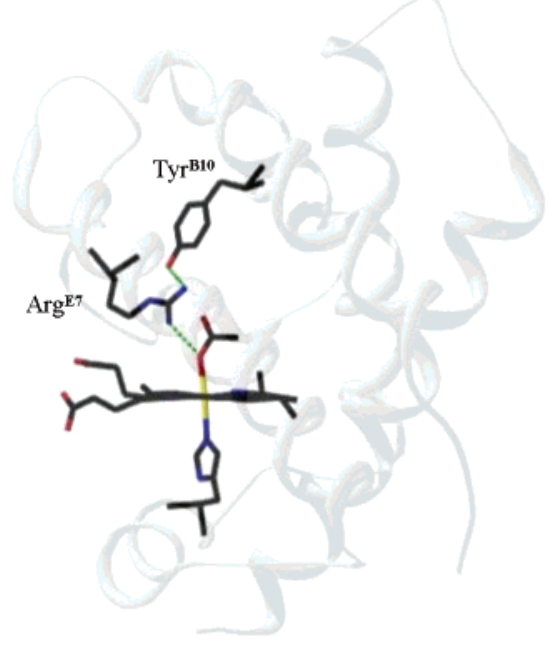

(C) $\mathrm{Arg}^{\mathrm{E7}} \mathrm{LbaCO}$ model

FIGURE 10: LbaCO model structures and wild-type MbCO. (A) Model for LbaCO. The acetomet-Lba structure (PDB entry 1BIN) was used as a starting point to explore possible interactions between $\mathrm{Tyr}^{\mathrm{B} 10}$ and $\mathrm{His}^{\mathrm{E} 7}$, which would be consistent with the measured IR spectra, kinetic parameters, and NMR data (Tables 1 and 2; 37, 38, 53). Minor changes to the side-chain torsion angles of these residues were made in the program $O$, allowing formation of a hydrogen bond between the $\mathrm{Tyr}^{\mathrm{B} 10}$ hydroxyl proton and the His ${ }^{\mathrm{E} 7} \mathrm{~N} \delta$ nonbonded electron pair. No highly unfavorable van der Waals overlaps were created in the process. The proposed hydrogen bonds are shown in green. (B) Crystal structure of $\mathrm{MbCO}$ (PDB 2MGK) (11). His ${ }^{\mathrm{E} 7}$ has more freedom of movement within the distal pocket of Mb to form an ideal hydrogen bond with the bound ligand than in the proposed Lba structure. (C) Model for Arg ${ }^{\mathrm{E} 7} \mathrm{LbaCO}_{\text {. His }}{ }^{\mathrm{E} 7}$ was replaced with Arg in the program $O$, and then the rotomers for $\mathrm{Tyr}^{\mathrm{B} 10}$ and $\mathrm{Arg}^{\mathrm{E} 7}$ were searched until a terminal $\mathrm{N}$ atom of the guanidinium group was within hydrogenbonding distance of the $\mathrm{O}$ atom of the $\mathrm{Tyr}^{\mathrm{B}}{ }^{10}$ side chain. This model shows a possible conformation where the guanidinium group of Arg ${ }^{\mathrm{E} 7}$ is held inside the distal pocket with hydrogen bonds to the first or second ligand atom and the Tyr ${ }^{\mathrm{B} 10}$ side chain.

conformation is supported by NMR investigations by Wright's group, who showed that the imidazole ring of $\mathrm{His}^{\mathrm{E} 7}$ is oppositely oriented in $\mathrm{LbaCO}$ compared to that found in MbCO $(37,38)$. In solution, the $\mathrm{C} \epsilon-\mathrm{H}$ proton in Lba is closer to the heme than the $\mathrm{C} \delta-\mathrm{H}$ proton, whereas the reverse is true in $\mathrm{MbCO}$ (38). The $\mathrm{C}-\mathrm{H}$ proton resonances for the side chains of $\mathrm{His}^{\mathrm{E} 7}$ and $\mathrm{Tyr}^{\mathrm{B} 10}$ can be calculated using a combination of the program SHIFTS (42), the PDB files for the observed crystal structure, and the model in Figure 10A. These calculated chemical shifts can then be compared to those reported by Morikis et al. (53) for LbaCO.

The chemical shifts calculated for the $\mathrm{His}^{\mathrm{E} 7} \mathrm{C} \beta$ protons in our model of LbaCO are 2.72 and 2.89 ppm and nearly identical to the values observed experimentally by Morikis et al. [2.73 and $2.88 \mathrm{ppm}$ (53)]. The calculated $\mathrm{C} \beta-\mathrm{H}$ shifts for the acetate-metLba structure are 3.26 and $3.27 \mathrm{ppm}$, indicating that the side chain is further from the heme plane when the larger acetate ligand is bound. More importantly, the predicted chemical shifts of the $\mathrm{His}^{\mathrm{E7}} \mathrm{C} \delta$ and $\mathrm{C} \epsilon$ protons, 6.75 and $4.82 \mathrm{ppm}$, respectively, are much closer to the observed values of 7.15 and $5.26 \mathrm{ppm}$ for $\mathrm{LbaCO}$ in solution than those calculated for acetate-metLba crystal structure, 7.04 and $8.11 \mathrm{ppm}$. The observed values for the $\mathrm{His}^{\mathrm{E} 7} \mathrm{C} \delta$ and $\mathrm{C} \epsilon$ protons require that the imidazole ring be rotated $180^{\circ}$ with respect to the orientation found in the metLba (Figure 2) and sperm whale MbCO (Figure 10B) crystal structures $(37,38)$. The predicted chemical shifts of the $\mathrm{Tyr}^{\mathrm{B} 10} \mathrm{C} \beta, \mathrm{C} \gamma$, and $\mathrm{C} \delta$ protons for the model $\mathrm{LbaCO}$ structure $(2.54,3.00,6.58$, and $6.38 \mathrm{ppm})$ are also closer to the observed values [2.66, 2.42, 6.4, and $6.03 \mathrm{ppm}(53)]$ than those calculated for the acetate-metLba crystal structure $(2.79,3.32,7.09$, and $6.69 \mathrm{ppm})$.
Thus, our structural interpretation in terms of direct hydrogen bonding between $\mathrm{His}^{\mathrm{E} 7}$ and $\mathrm{Tyr}^{\mathrm{B} 10}$ is consistent with all reported IR, ligand binding, and solution NMR data. However, more systematic modeling using molecular dynamics and energy minimization is needed. The ultimate verification of the model will come with NMR or crystal structure determinations of the wild-type $\mathrm{LbaO}_{2}$ and $\mathrm{LbaCO}$ complexes.

The unusual properties of $\mathrm{Arg}^{\mathrm{E} 7} \mathrm{Lba}$ can also be rationalized by a distal pocket structure similar to that proposed for the native protein (Figure 10C). In Lba, the guanidino group can potentially swing inward and form hydrogen bonds with both the phenol side chain of $\mathrm{Tyr}^{\mathrm{B} 10}$ and bound ligands. In the case of the relatively apolar $\mathrm{FeCO}$ complex, the interaction with the bound ligand is weak, and $15-20 \%$ of the population of mutant conformers has an apolar pocket with $v_{\mathrm{CO}} \geq 1960 \mathrm{~cm}^{-1}$. However, in combination with the $\mathrm{Tyr}^{\mathrm{B} 10}$ side chain, the partial negative charge on the ligand atoms of the $\mathrm{FeO}_{2}$ complex appears to cause $\mathrm{Arg}^{\mathrm{E} 7}$ to adopt a completely "in" conformation (Figure 10C). As a result, the $\mathrm{Arg}^{\mathrm{B} 7}$ mutation in $\mathrm{LbaO}_{2}$ causes a 30 -fold decrease in $k_{\mathrm{O} 2}$, producing a protein with ultrahigh $\mathrm{O}_{2}$ affinity $\left(P_{50} \leq 1 \mathrm{nM}\right.$; Table 2).

Physiological Importance of the B10 Amino Acid. The role of the B10 amino acid in regulating ligand binding in $\mathrm{Hbs}$ is now widely accepted $(43,55,56)$. As described in this work, the naturally occurring $\mathrm{Tyr}^{\mathrm{B} 10}$ side chain in soybean and cowpea $\mathrm{Lb}$ serves to "trap" $\mathrm{His}^{\mathrm{E} 7}$ in a single conformation that provides weaker stabilization to bound ligands than is observed in mammalian Mbs. This helps Lb maintain an oxygen affinity appropriate for its physiological function. In almost all mammalian Mbs and Hbs, the B10 residue is 
a Leu. As a result, the distal pocket has significant "empty" space, and dissociated ligands can move easily toward the protein interior underneath the sec-butyl side chain, occupying what is called the " $\mathrm{B}$ " geminate state in laser photolysis experiments. This empty space adjacent to the bound ligand appears to be conserved to facilitate ligand capture and release in an otherwise relatively rigid protein structure. It may also be conserved to allow formation of the four-atom peroxynitrite intermediate that occurs during the dioxygenation of $\mathrm{NO}$ by bound $\mathrm{O}_{2}$, a process that plays a key role in detoxifying $\mathrm{NO}$ in both myocytes and circulating blood (57-60). Introduction of $\mathrm{Phe}^{\mathrm{B} 10}, \mathrm{Tyr}^{\mathrm{B} 10}$, or $\mathrm{Trp}^{\mathrm{B} 10}$ into mammalian Mbs and Hbs fills this empty space, inhibiting the rate of both ligand binding and NO dioxygenation (60).

The presence of both $\mathrm{His}^{\mathrm{E} 7}$ and $\mathrm{Tyr}^{\mathrm{B} 10}$ in Hbs is unusual and appears to require a larger and more flexible active site. In the case of sperm whale $\mathrm{Mb}$, the introduction of a Tyr at the $\mathrm{B} 10$ position leads to the formation of an unstable protein with kinetic heterogeneity and multiple $v_{\mathrm{CO}}$ bands. When the distal His is replaced with more flexible amino acids in $\mathrm{Mb}$ double mutants, the $\mathrm{Tyr}^{\mathrm{B} 10}$ side chain appears to interact favorably with bound ligands (Figure 9; Table 2). Strong hydrogen bonds between bound ligands and $\mathrm{Tyr}^{\mathrm{B} 10}$ occur in many natural ultrahigh affinity $\mathrm{Hbs}$, such as Ascaris $\mathrm{Hb}$, and most of these proteins have Gln at the E7 position (13). Ascaris $\mathrm{Hb}$ resembles Lba in having a B10 Tyr, but it has a more compact distal heme pocket such that if $\mathrm{Gln}^{\mathrm{E} 7}$ is replaced with His, the resulting protein is hexacoordinated unlike wtLba (61). CO-bound Ascaris $\mathrm{Hb}$ also exhibits close proximity between the $\mathrm{B} 10$ phenolic proton and bound $\mathrm{CO}$, suggesting that $\mathrm{Tyr}^{\mathrm{B} 10}$ in Ascaris $\mathrm{Hb}$ interacts directly with the bound ligand to increase affinity $(61)$, whereas $\mathrm{Tyr}^{\mathrm{B} 10}$ in Lba has an indirect and destabilizing effect. Hence, variation in the positioning of the $\mathrm{Tyr}^{\mathrm{B} 10}$ as a function of E7 substitutions and the resulting alteration in the flexibility of distal heme pockets impart important physiological functions.

Correlations of CO IR Stretching Frequencies and Rate of $\mathrm{O}_{2}$ Release by Lba. Phillips et al. (19) showed that there is a strong, inverse, linear correlation between the electrostatic field adjacent to bound $\mathrm{CO}$ and its stretching frequency. Recently, Franzen (32) has presented a more sophisticated analysis of the hydrogen-bonding and electrostatic potentials in these proteins. Both types of analyses demonstrate unequivocally that $v_{\mathrm{CO}}$ is an inverse measure of the hydrogenbonding potential and/or electric field adjacent to the bound ligand atoms. Low values of $v_{\mathrm{CO}}$ correspond to positive electrostatic fields and strong hydrogen bond donation, whereas high values of $v_{\mathrm{CO}}$ correspond to no hydrogen bonding and/ or negative electrostatic fields.

Surprisingly, there is only a weak correlation between the average value of $v_{\mathrm{CO}}$ and the rate of $\mathrm{CO}$ dissociation, primarily because the $\mathrm{FeCO}$ complex is relatively nonpolar and the variation in $k_{\mathrm{CO}}$ is small [ $\leq 30$-fold between the various $\mathrm{Mb}$ and Lba mutants listed in Table $2(18,19)]$. In contrast, a strong linear correlation is observed between the measured values of $\bar{\nu}_{\mathrm{CO}}$ and the logarithm of the rate constant for $\mathrm{O}_{2}$ dissociation (Figure $11 ; 19$ )), presumably because the $\mathrm{FeO}_{2}$ complex is highly polar. A stabilizing positive electrostatic field and hydrogen-bonding potential provides a simple explanation for the 3000 -fold variation in $k_{\mathrm{O} 2}$ for $\mathrm{Mb}$ distal pocket mutants. A significantly poorer correlation $\left(r^{2}\right.$ $=0.50)$ between $\bar{v}_{\mathrm{CO}}$ and $\log \left(k_{\mathrm{O} 2}\right)$ is observed for the series

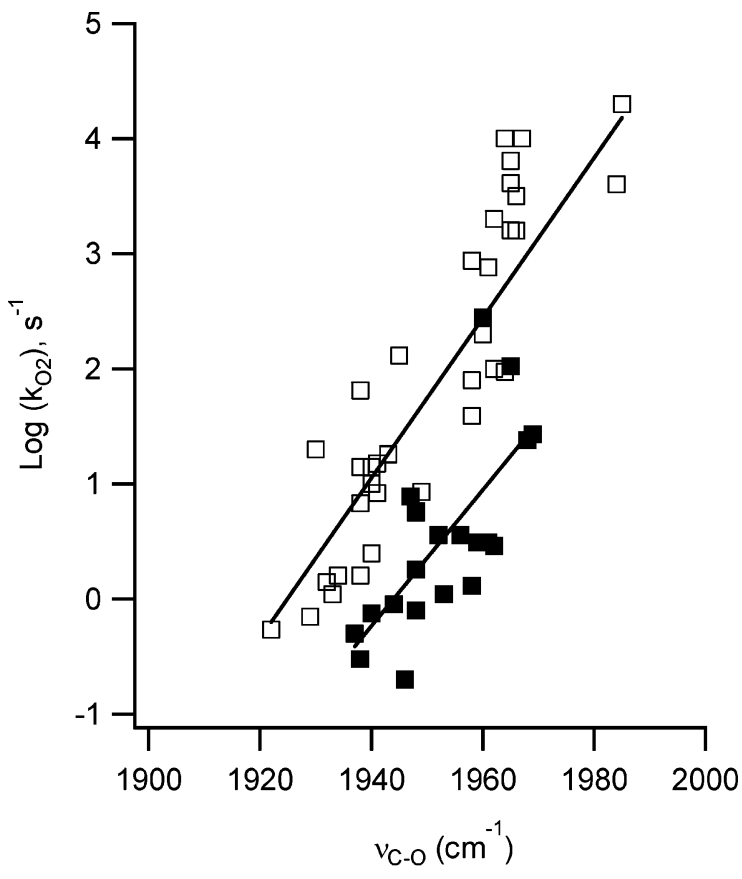

FIGURE 11: Correlation between the stretching frequencies of $\mathrm{CO}$ bound to wild-type $\mathrm{Lba}, \mathrm{Mb}$, various mutant proteins, and their corresponding oxygen dissociation rate constants. There is a strong linear correlation $\left(r^{2}=0.82\right)$ between $\bar{v}_{\mathrm{CO}}$ and $\log \left(k_{\mathrm{O} 2}\right)$ for the 31 different sperm whale Mbs (open squares), which are listed in Table 2 and described in Phillips et al. (19). A significant but poorer correlation $\left(r^{2}=0.50\right)$ is observed between $\bar{v}_{\mathrm{CO}}$ and $\log \left(k_{\mathrm{O} 2}\right)$ for the series of Lba mutants listed in Table 2 (solid squares).

of Lb mutants listed in Table 2 (Figure 11). The cause of the variance is flexibility of the distal pocket, particularly the conformation of the E7 side chain, which probably changes between the $\mathrm{CO}$ and $\mathrm{O}_{2}$ complexes of Lba.

$\mathrm{Arg}^{\mathrm{E} 7} \mathrm{Lba}$ provides a good example of large apparent differences between the $\mathrm{O}_{2}$ and $\mathrm{CO}$ complexes. The IR spectrum of the $\mathrm{CO}$ complex shows conformational heterogeneity with a broad peak at moderately low frequency and another broad peak at moderately high frequency. Because $\bar{v}_{\mathrm{CO}}$ is $1946 \mathrm{~cm}^{-1}$, only a small decrease in $k_{\mathrm{O} 2}$ is predicted. However, the observed rate constant decreases 30-fold, suggesting strongly that the $\operatorname{Arg}^{\mathrm{E} 7}$ side chain has completely swung into the distal pocket, stabilizing bound $\mathrm{O}_{2}$ due to its partial negative charge (Figure 10C). A distal Arg side chain has been shown to stabilize bound oxygen in Aplysia limacina $\mathrm{Mb}$ (62) and in the DOS-oxygen sensor protein from Bradyrhizobium japonicum, which has a very low rate of $\mathrm{O}_{2}$ dissociation (63).

The nearly parallel fitted lines in the plots of $\log \left(k_{\mathrm{O} 2}\right)$ versus $v_{\mathrm{CO}}$ shown in Figure 11 demonstrate that the general electrostatic/hydrogen bonding mechanism for preferentially regulating $\mathrm{O}_{2}$ dissociation applies to both $\mathrm{Mb}$ and $\mathrm{Lba}$. The line is displaced in Lba probably due to proximal stabilization of ligand binding, causing lower $k_{\mathrm{O} 2}$ values. The electrostatic mechanism and the proposed structure in Figure 10A explain qualitatively all of the large changes produced by distal pocket mutations in Lba. Replacement of the distal His with large apolar residues that exclude water from the distal pocket cause increases in $v_{\mathrm{CO}}$ and $k_{\mathrm{O} 2}$ (Table 2). Replacement of $\mathrm{Tyr}^{\mathrm{B} 10}$ with apolar amino acids causes the appearance of strong low-frequency $v_{\mathrm{CO}}$ bands and decreases in $k_{\mathrm{O} 2}$ (Table 2 ) because the distal His is free to adopt multiple conforma- 
tions, some of which form strong hydrogen bonds with bound ligands. When both $\mathrm{Tyr}^{\mathrm{B} 10}$ and $\mathrm{His}^{\mathrm{E}}{ }^{\mathrm{T}}$ are replaced with apolar amino acids, the resulting Lba double mutant shows an IR spectrum identical to that of $\mathrm{Mb}$ with a hydrophobic distal pocket and a large $\mathrm{O}_{2}$ dissociation rate constant.

\section{ACKNOWLEDGMENT}

We thank Dr. Pawel M. Strozycki for lupin leghemoglobin cDNA.

\section{REFERENCES}

1. Appleby, C. (1974) in The Biology of Nitrogen Fixation (Quispel, A., Ed.), pp 521-544, North-Holland Publishing, Amsterdam, The Netherlands.

2. Wittenberg, J., Bergensen, F., Appleby, C., and Turner, G. (1974) Facilitated oxygen diffusion. The role of leghemoglobin in nitrogen fixation by bacteroids isolated from soybean root nodules, J. Biol. Chem. 249, 4057-4066.

3. Arutyunyan, É. G., Kuranova, I. P., Vainshtein, B. K., and Steigemann, W. (1980) X-ray structural investigation of leghemoglobin: VI. Structure of acetate-ferrileghemoglobin at a resolution of $2.0 \AA$, Sov. Phys. Cryst. 25, 43-58.

4. Hargrove, M. S., Barry, J. K., Brucker, E. A., Berry, M. B., Phillips, G. N., Jr., Olson, J. S., Arredondo-Peter, R., Dean, J. M., Klucas, R. V., and Sarath, G. (1997) Characterization of recombinant soybean leghemoglobin a and apolar distal histidine mutants, J. Mol. Biol. 266, 1032-1042.

5. Kundu, S., and Hargrove, M. S. (2003) Distal heme pocket regulation of ligand binding and stability in soybean leghemoglobin, Proteins 50, 239-248.

6. Kundu, S., Snyder, B., Das, K., Chowdhury, P., Park, J., Petrich, J. W., and Hargrove, M. S. (2002) The leghemoglobin proximal heme pocket directs oxygen dissociation and stabilizes bound heme, Proteins 46, 268-277.

7. Patel, N., Jones, D., and Raven, E. (2000) Investigation of the haem-nicotinate interaction in leghaemoglobin. Role of hydrogen bonding, Eur. J. Biochem. 267, 2581-2587.

8. Kundu, S., Trent, J. T., III, and Hargrove, M. S. (2003) Plants, humans, and hemoglobins, Trends Plant Sci. 8, 387-393.

9. Chowdhury, P., Kundu, S., Halder, M., Das, K., Hargrove, M. S., and Petrich, J. W. (2003) Effects of distal pocket mutations on the geminate recombination of $\mathrm{NO}$ with leghemoglobin on the picosecond timescale, J. Phys. Chem. B 107, 9122-9127.

10. Takano, T. (1977) Structure of myoglobin refined at $2.0 \AA$ resolution: II. Structure of deoxymyoglobin from sperm whale, J. Mol. Biol. 110, 569-584.

11. Quillin, M. L., Arduini, R. M., Olson, J. S., and Phillips, G. N., Jr. (1993) High-resolution crystal structures of distal histidine mutants of sperm whale myoglobin, J. Mol. Biol. 234, 140-155.

12. Barrick, D. (1994) Replacement of the proximal ligand of sperm whale myoglobin with free imidazole in the mutant His-93 $\rightarrow$ Gly, Biochemistry 33, 6546-6554.

13. Draghi, F., Miele, A., Travaglini-Allocatelli, C., Vallone, B., Brunori, M., Gibson, Q., and Olson, J. (2002) Controlling ligand binding in myoglobin by mutagenesis, J. Biol. Chem. 277, 75097519.

14. Olson, J. S., and Phillips, G. N., Jr. (1997) Myoglobin discriminates between $\mathrm{O}_{2}, \mathrm{NO}$, and $\mathrm{CO}$ by electrostatic interactions with the bound ligand, J. Biol. Inorg. Chem. 2, 544-552.

15. Springer, B. A., Sligar, S. G., Olson, J. S., and Phillips, G. N., Jr. (1994) Mechanisms of ligand recognition in myoglobin, Chem. Rev. 94, 699-714.

16. Caughey, W. S., Alben, J. O., McCoy, S., Boyer, S. H., Carache, S., and Hathaway, P. (1969) Differences in the infrared stretching frequency of carbon monoxide bound to abnormal hemoglobins, Biochemistry 8, 59-62.

17. Sage, J. T., Morikis, D., and Champion, P. M. (1991) Spectroscopic studies of myoglobin at low $\mathrm{pH}$ : heme structure and ligation, Biochemistry 30, 1227-1237.

18. Li, T., Quillin, M. L., Phillips, G. N., Jr., and Olson, J. S. (1994) Structural determinants of the stretching frequency of $\mathrm{CO}$ bound to myoglobin, Biochemistry 33, 1433-1446.
19. Phillips, G. N. J., Teodoro, M. L., Li, T., Smith, B., and Olson, J. S. (1999) Bound CO is a molecular probe of electrostatic potential in the distal pocket of myoglobin, J. Phys. Chem. B 103, 88178829.

20. Ray, G. B., Li, X.-Y., Ibers, J. A., Sessler, J. L., and Spiro, T. G. (1994) How far can proteins bend the FeCO unit? Distal polar and steric effects in heme proteins and models, J. Am. Chem. Soc. 116, 162-176.

21. Shimada, H., and Caughey, W. S. (1982) Dynamic protein structures: Effects of $\mathrm{pH}$ on conformer stabilities at the ligandbinding site of bovine heart myoglobin carbonyl, J. Biol. Chem. 257, 11893-11900.

22. Ansari, A., Berendzen, J., Braunstein, D., Cowen, B. R., Frauenfelder, H., Hong, M. K., Iben, E. T., Johnson, J. B., Ormos, P., Sauke, T. B., Scholl, R., Schulte, A., Steinbach, P. J., Vittitow, J., and Young, R. D. (1987) Rebinding and relaxation in the myoglobin pocket, Biophys. Chem. 26, 337-355.

23. Ormos, P., Braunstein, D., Frauenfelder, H., Hong, M. K., Lin, S.-L., Sauke, T. B., and Young, R. D. (1988) Orientation of carbon monoxide and structure-function relationship in carbonmonoxymyoglobin, Proc. Natl. Acad. Sci. U.S.A. 85, 8492-8496.

24. Decatur, S. M., and Boxer, S. G. (1995) A test of the role of electrostatic interactions in determining the $\mathrm{CO}$ stretch frequency in carbonmonoxymyoglobin, Biochem. Biophys. Res. Commun. 212, 159-164.

25. Potter, W. T., Hazzard, J. H., Choc, M. G., Tucker, M. P., and Caughey, W. S. (1990) Infrared spectra of carbonyl hemoglobins: Characterization of dynamic heme pocket conformers, Biochemistry 29, 6283-6295.

26. Frauenfelder, H., Parak, F., and Young, R. D. (1988) Conformational substates in proteins, Annu. Rev. Biophys. Chem. 17, 451479 .

27. Hong, M. K., Braunstein, D., Cowen, B. R., Frauenfelder, H., Iben, I. E., Mourant, J. R., Ormos, P., Scholl, R., Schulte, A., Steinbach, P. J., Xie, A.-H., and Young, R. D. (1990) Conformational substates and motions in myoglobin: External influences on structure and dynamics, Biophys. J. 58, 429-436.

28. Johnson, J. B., Lamb, D. C., Frauenfelder, H., Muller, J. D. McMahon, B., Nienhaus, G. U., and Young, R. D. (1996) Ligand binding to heme proteins. VI. Interconversion of taxonomic substates in carbonmonoxymyoglobin, Biophys J. 71, 1563-1573.

29. Li, X.-Y., and Spiro, T. G. (1988) Is bound CO linear or bent in heme proteins? Evidence from resonance Raman and infrared spectroscopic data, J. Am. Chem. Soc. 110, 6024-6033.

30. Oldfield, E., Guo, K., Augspurger, J. D., and Dykstra, C. E. (1991) A molecular model for the major conformational substates in heme proteins, J. Am. Chem. Soc. 113, 7537-7541.

31. Park, K. D., Guo, K., Adebodun, F., Chiu, M. L., Sligar, S. G., and Oldfield, E. (1991) Distal and proximal ligand interactions in heme proteins: Correlations between $\mathrm{C}-\mathrm{O}$ and $\mathrm{Fe}-\mathrm{C}$ vibrational frequencies, oxygen-17 and carbon-13 nuclear magnetic resonance chemical shifts, and oxygen-17 nuclear quadrupole coupling constants in $\mathrm{C}^{17} \mathrm{O}$ - and ${ }^{13} \mathrm{CO}$-labeled species, Biochemistry 30, 2333-2347.

32. Franzen, S. (2002) An electrostatic model for the frequency shifts in the carbonmonoxy stretching band of myoglobin: correlation of hydrogen bonding and the stark tuning rate, J. Am. Chem. Soc. 124, 13271-13281.

33. Spiro, T. G., and Kozlowski, P. M. (1998) Discordant results on $\mathrm{FeCO}$ deformability in heme proteins reconciled by density functional theory, J. Am. Chem. Soc. 120, 4524-4525.

34. Makinen, M. W., Houtchens, R. A., and Caughey, W. S. (1979) Structure of carboxymyoglobin in crystals and in solution, Proc. Natl. Acad. Sci. U.S.A. 76, 6042-6046.

35. Caughey, W. S., Shimada, H., Miles, G. C., and Tucker, M. P. (1981) Dynamic protein structures: infrared evidence for four discrete rapidly interconverting conformers at the carbon monoxide binding site of bovine heart myoglobin, Proc. Natl. Acad. Sci. U.S.A. 78, 2903-2907.

36. Fuchsman, W. H., and Appleby, C. A. (1979) $\mathrm{CO}$ and $\mathrm{O}_{2}$ complexes of soybean leghemoglobins: $\mathrm{pH}$ effects upon infrared and visible spectra. comparisons with $\mathrm{CO}$ and $\mathrm{O}_{2}$ complexes of myoglobin and hemoglobin, Biochemistry 18, 1309-1321.

37. Mabbutt, B., Appleby, C. A., and Wright, P. E. (1983) NMR studies of oxyleghemoglobin: Assignment of distal histidine proton resonances and evidence for $\mathrm{pH}$-dependent changes in conformation, Biochim. Biophys. Acta 749, 281-288.

38. Mabbutt, B., and Wright, P. E. (1985) Assignment of heme and distal amino acid resonances in the ${ }^{1} \mathrm{H}-\mathrm{NMR}$ spectra of the carbon 
monoxide and oxygen complexes of sperm whale myoglobin, Biochim. Biophys. Acta 832, 175-185.

39. Arredondo-Peter, R., Moran, J. F., Sarath, G., Luan, P., and Klucas, R. V. (1997) Molecular cloning of the cowpea leghemoglobin II gene and expression of its cDNA in Escherichia coli. Purification and characterization of the recombinant protein, Plant Physiol. 114, 493-500.

40. Rohlfs, R. J., Mathews, A. J., Carver, T. E., Olson, J. S., Springer, B. A., Egeberg, K. D., and Sligar, S. G. (1990) The effects of amino acid substitution at position E7 (residue 64) on the kinetics of ligand binding to sperm whale myoglobin, J. Biol. Chem. 265, $3168-3176$.

41. Jones, T., Zou, J., Cowan, S., and Kjeldgaard, M. (1991) Improved methods for building protein models in electron density maps and the location of errors in these models, Acta Crystallogr. A47, 110119.

42. Xu, X.-P., and Case, D. A. (2002) Probing multiple effects on ${ }^{15} \mathrm{~N},{ }^{13} \mathrm{C}$ alpha, ${ }^{13} \mathrm{C}$ beta and ${ }^{13} \mathrm{C}$ chemical shifts in peptides using density functional theory, Biopolymers 65, 408-423.

43. Carver, T. E., Brantley, R. E., Jr., Singleton, E. W., Arduini, R. M., Quillin, M. L., Phillips, G. N., Jr., and Olson, J. S. (1992) A novel site-directed mutant of myoglobin with an unusually high $\mathrm{O}_{2}$ affinity and low autoxidation rate, J. Biol. Chem. 267, 1444314450.

44. Springer, B. A., Egeberg, K. D., Sligar, S. G., Rohlfs, R. J., Mathews, A. J., and Olson, J. S. (1989) Discrimination between oxygen and carbon monoxide and inhibition of autoxidation by myoglobin. Site-directed mutagenesis of the distal histidine, $J$. Biol. Chem. 264, 3057-3060.

45. Shimada, H., Dong, A., Matsushima-Hibiya, Y., Ishimura, Y., and Caughey, W. S. (1989) Distal His $\rightarrow$ Arg mutation in bovine myoglobin results in a ligand binding site similar to the abnormal beta site of hemoglobin zurich ( $\beta 63 \mathrm{His} \rightarrow \mathrm{Arg}$ ), Biochem. Biophys. Res. Commun. 158, 110-114.

46. Tucker, P. W., Phillips, S. E. V., Perutz, M. F., Houtchens, R., and Caughey, W. S. (1978) Structure of hemoglobins Zürich [His E7(63) $\beta \rightarrow$ Arg] and Sydney [Val E11(67) $\beta \rightarrow$ Ala] and role of the distal residues in ligand binding, Proc. Natl. Acad. Sci. U.S.A. $75,1076-1080$.

47. Quillin, M. L., Li, T., Olson, J. S., Phillips, G. N., Jr., Dou, Y., Ikeda-Saito, M., Regan, R., Carlson, M., Gibson, Q. H., Li, H., and Elber, R. (1995) Structural and functional effects of apolar mutations of the distal valine in myoglobin, J. Mol. Biol. 245, 416-436.

48. Lambright, D. G., Balasubramanian, S., Decatur, S. M., and Boxer, S. G. (1994) Anatomy and dynamics of a ligand-binding pathway in myoglobin: The roles of residues $45,60,64$, and 68 , Biochemistry 33, 5518-5525.

49. Smerdon, S. J., Dodson, G. G., Wilkinson, A. J., Gibson, Q. H., Blackmore, R. S., Carver, T. E., and Olson, J. S. (1991) Distal pocket polarity in ligand binding to myoglobin: Structural and functional characterization of a threonine ${ }^{68}$ (E11) mutant, Biochemistry 30, 6252-6260.

50. Sikorski, M. M., Topunov, A. F., Strozycki, P. M., Vorgias, C. E., Wilson, K. S., and Legocki, A. B. (1995) Cloning and expression of plant leghemoglobin cDNA of Lupinus luteus in Escherichia coli and purification of the recombinant protein, Plant Sci. 108, 109-117.
51. Gibson, Q. H., Wittenberg, J. B., Wittenberg, B. A., Bogusz, D., and Appleby, C. A. (1989) The kinetics of ligand binding to plant hemoglobins: structural implications, J. Biol. Chem. 264, 100107.

52. Harutyunyan, E. H., Safonova, T. N., Kuranova, I. P., Popov, A. N., Teplyakov, A. V., Obmolova, G. V., Valnshtein, B. K., Dodson, G. G., and Wilson, J. C. (1996) The binding of carbon monoxide and nitric oxide to leghaemoglobin in comparison with other haemoglobins, J. Mol. Biol. 264, 152-161.

53. Morikis, D., Lepre, C. A., and Wright, P. E. (1994) ${ }^{1} \mathrm{H}$ resonance assignments and secondary structure of the carbon monoxide complex of soybean leghemoglobin determined by homonuclear two-dimensional and three-dimensional NMR spectroscopy, Eur. J. Biochem. 219, 611-626.

54. Ellis, P. J., Appleby, C. A., Guss, J. M., Hunter, W. N., Ollis, D. L., and Freeman, H. C. (1997) Structure of the ferric soybean leghemoglobin $a$ nicotinate at 2.3 A resolution, Acta Crystallogr. D53, 302-310.

55. Yang, J., Kloek, A., Goldberg, D., and Mathews, F. (1995) The structure of Ascaris hemoglobin domain I at $2.2 \AA$ resolution: Molecular features of oxygen avidity, Proc. Natl. Acad. Sci. U.S.A. 92, 4224-4228.

56. Pesce, A., Dewilde, S., Kiger, L., Milani, M., Ascenzi, P., Marden, M., Hauwaert, M.-L. V., Vanfleteren, J., Moens, L., and Bolognesi, M. (2001) Very high-resolution structure of a trematode hemoglobin displaying a TyrB10-TyrE7 heme distal residue pair and high oxygen affinity, J. Mol. Biol 309, 1153-1164.

57. Eich, R. F., Li, T., Lemon, D. D., Doherty, D. H., Curry, S. R., Aitken, J. F., Mathews, A. J., Johnson, K. A., Smith, R. D., Phillips, G. N., Jr., and Olson, J. S. (1996) Mechanism of NOinduced oxidation of myoglobin and hemoglobin, Biochemistry 35, 6976-6983.

58. Doherty, D., Doyle, M. P., Curry, S. R., Vali, R., Fattor, T., Olson, J., and Lemon, D. (1998) The rate of reaction with NO determines the hypertensive effect of cell-free hemoglobin, Nat. Biotechnol. 16, 672-676.

59. Herold, S., Exner, M., and Boccini, F. (2003) The mechanism of the peroxynitrite-mediated oxidation of myoglobin in the absence and presence of carbon dioxide, Chem. Res. Toxicol. 16, 390402 .

60. Dou, Y., Maillett, D. H., Eich, R. F., and Olson, J. S. (2002) Myoglobin as a model system for designing heme protein based blood substitutes, Biophys. Chem. 98, 127-148.

61. Das, T. K., Samuni, U., Lin, Y., Goldberg, D. E., Rousseau, D. L., and Friedman, J. M. (2004) Distal heme pocket conformers of carbonmonoxy derivatives of Ascaris hemoglobin: Evidence of conformational trapping in porous sol-gel matrices, J. Biol. Chem. 279, 10433-10441.

62. Conti, E., Moser, C., Rizzi, M., Mattevi, A., Lionetti, C., Coda, A., Ascenzi, P., Brunori, M., and Bolognesi, M. (1993) X-ray crystal structure of ferric Aplysia limacina myoglobin in different liganded states, J. Mol. Biol 233, 498-508.

63. Dunham, C. M., Dioum, E. M., Tuckerman, J. R., Gonzalez, G., Scott, W. G., and Gilles-Gonzalez, M. A. (2003) A distal arginine in oxygen-sensing heme-PAS domains is essential to ligand binding, signal transduction, and structure, Biochemistry 42, 7701-7708.

BI049848G 